\title{
One Year of Evidence on Mental Health Disorders in China during the COVID-19 Crisis -
}

\section{A Systematic Review and Meta-Analysis}

Xi Chen ${ }^{\text {a }}$, Jiyao Chen ${ }^{b}$, Meimei Zhang ${ }^{\mathrm{c}}$, Richard Z. Chen ${ }^{\mathrm{d}}$, Rebecca Kechen Dong ${ }^{\mathrm{e}}$, Zhe Dong

${ }^{\mathrm{f}}$, Yingying Ye ${ }^{\mathrm{g}}$, Lingyao Tong ${ }^{\mathrm{h}}$, Bryan Z. Chen ${ }^{\mathrm{d}}$, Ruiying Zhao ${ }^{\mathrm{h}}$, Wenrui Cao ${ }^{\mathrm{i}}$, Peikai Li ${ }^{\mathrm{i}}$, Stephen X. Zhang ${ }^{j *}$

\section{Author affiliations}

a Chinese Open Science Network, China

b College of Business, Oregon State University, Corvallis, OR 97330, USA

c Department of Speech-Language-Hearing Sciences, Texas Tech University Health Sciences

Center, Lubbock, TX 79430, USA

d Crescent Valley High School, Corvallis, OR 97330, USA

e School of Management, University of South Australia, Adelaide, Australia

f College of Psychology, Capital Normal University, Beijing, China

g Department of Psychology, Zhejiang University of Technology, Hangzhou, China

h Department of Clinical, Neuro- and Developmental Psychology, Vrije Universiteit Amsterdam, Amsterdam, the Netherlands

i Department of Social, Health and Organizational Psychology, Utrecht University, Utrecht, the Netherlands

j Faculty of Professions, University of Adelaide, Adelaide, Australia

*Correspondence to: Stephen X. Zhang, Associate Professor, University of Adelaide; 9-28

Nexus10 Tower, 10 Pulteney St, Adelaide SA 5000, Australia, stephen.X.zhang@gmail.com 


\begin{abstract}
This paper provides a systematic review and meta-analysis on the prevalence rate of mental health issues of general population, general and frontline healthcare workers (HCWs) in China over one year of the COVID-19 crisis. We systematically searched PubMed, Embase, Web of Science, and Medrxiv at November 16th, 2020, pooled data using random-effects meta-analyses to estimate the prevalence rates, and ran meta-regression to tease out the heterogeneity. The meta-regression results uncovered several predictors of the prevalence rates, including severity, type of mental issues, population, sampling location, and study quality. Pooled prevalence rates are significantly different from, yet largely between, the findings of previous meta-analyses, suggesting the results of our larger study are consistent with yet more accurate than the findings of the smaller, previous meta-analyses. The prevalence rates of distress and insomnia and those of frontline HCWs are higher suggest future research and interventions should pay more attention to those mental outcomes and populations. Our findings suggest a need to examine the prevalence rates at varying levels of severity. The one-year cumulative evidence on sampling locations (Wuhan vs. non-Wuhan) corroborates the typhoon eye effect theory.
\end{abstract}

Keywords: epidemic; general population; healthcare workers; frontline healthcare workers

Trial registration: CRD4202022059 
medRxiv preprint doi: https://doi.org/10.1101/2021.02.01.21250929; this version posted April 30, 2021. The copyright holder for this preprint (which was not certified by peer review) is the author/funder, who has granted medRxiv a license to display the preprint in perpetuity.

It is made available under a CC-BY-ND 4.0 International license .

\section{INTRODUCTION}

Since its first publicly known cases in Wuhan, China, on November 17, 2019, the COVID-19 (coronavirus disease 2019) crisis has become one of the worst epidemics in human record (World Health Organization, 2020). The sudden outburst of this highly infectious disease and the containment measures such as quarantine and social distancing have posed an unprecedented disruption on the life and work of the general population and healthcare workers (HCWs) (Douglas et al., 2020; Zhang et al., 2020h). Their mental health conditions under the COVID-19 epidemic have been documented first and most extensively to date in China (Bareeqa et al., 2020; Pappa, 2020). The accumulating number of such studies has triggered several rapid meta-analyses (Bareeqa et al., 2020; Kisely et al., 2020; Krishnamoorthy et al., 2020; Pappa, 2020; Ren et al., 2020a; Salari et al., 2020b), which have provided important initial evidence on the prevalence of mental issues at the onset of the COVID-19 crisis. One year into the COVID-19 crisis, from November 17, 2019, to November 16, 2020, we see the values of a systematic review and meta-analysis to contribute above and beyond these meta-analyses in four major directions.

First, rapid meta-analyses generally include a dozen studies (Pappa, 2020; Ren et al., 2020a; Salari et al., 2020a), most from the onset of the COVID-19 crisis; hence new systematic reviews and meta-analyses are needed to update the evidence that quickly accumulates. Our pooled prevalence rates are significantly different from, yet largely between, the findings of previous meta-analyses, suggesting our larger meta-analysis is consistent with yet revises the findings of the much smaller, previous meta-analyses. The significance of the difference between our much larger meta-analysis and the previous studies suggests a need to update meta-analyses continuously to provide more accurate estimates of the prevalence rates of mental illness during this ongoing COVID-19 epidemic. 
Second, early rapid meta-analysis papers often pooled different mental disorders or distinct populations together due to the smaller numbers of studies included. However, such practices inadvertently contribute to the differences in their prevalence rates. Despite the fact that individual papers often use and report varying levels of cutoff values, most metaanalyses report the prevalence rates of mental health only by mild symptoms' severity e.g., (Luo et al., 2020; Pappa et al., 2020). We are able to identify the major populations in the published studies (the general population, HCWs, and frontline HCWs who deal with COVID-19 patients), the major mental health outcomes (anxiety, depression, insomnia, distress, and PTSD), and the severity of outcomes (above mild, above moderate, and above severe). Moreover, we run subgroup analysis and meta-regression to reveal important differences between the mental disorders.

Third, given the large heterogeneity in terms of not only the COVID cases and deaths but also the containment strategies and hospital capacities and readiness to handle COVID-19 cases across countries(Jahanshahi et al., 2020; Zhuo et al., 2020), there are some benefits to focusing on a single country. China seems to be the first country that experienced the COVID crisis and has had a sufficient number of empirical studies to conduct such a meta-analysis.

Fourth, given our scope of the systematic review over a year of the COVID-19 crisis, our work provides a more comprehensive assessment of evidence, which is urgently needed to guide future mental health papers in the continued global pandemic. Furthermore, based on a year of mental health papers under COVID-19, we observe and provide a list of concrete issues in individual mental health papers to guide this important and proliferating stream of research.

\section{METHODS}


This systematic review and meta-analysis was conducted in accordance with the Preferred Reporting Items for Systematic Reviews and Meta-Analyses (PRISMA) statement 2019 and registered in the International Prospective Register of Systematic Reviews (PROSPERO: CRD42020220592).

\subsection{Data Sources and Search Strategy}

We conducted a comprehensive literature search in the databases of PubMed, Embase, and Web of Science. Our search query, shown in Table S1, was entered with Boolean operators to search the titles, abstracts, keywords, and subject headings (for example, Mesh terms) in each database. To account for preprints, we searched medRxiv (medrxiv.org). We started our search on November 10, 2020, and finalized it on November 16, 2020, one year after the first publicly known COVID-19 case (Bryner, March 14, 2020), in order to cover the first year of the COVID-19 epidemic. In addition, we checked the references of earlier rapid meta-analyses to identify other studies that may fit this review. Figure 1 details the flow chart of our search process.

\subsection{Selection Criteria}

The studies are included in our meta-analysis based on the following criteria:
a. Context: COVID-19 epidemic in China
b. Population: frontline HCWs, general HCWs, and general adult population
c. Outcome: at least one mental disorder outcomes, e.g., anxiety, depression, distress, general psychological symptoms (GPS), insomnia, and PTSD
d. Instrument: validated scales with cutoff points for the mental health outcomes
e. Language: English.

According, we excluded studies that meet the following criteria: 
a. Population: children, adolescents, or specific niche adult populations such as COVID-19 patients, inpatients, or other patients, adults under quarantine, pregnant/postpartum women

b. Methodological approaches: non-primary studies such as reviews or meta-analyses, qualitative or case studies without a validated instrument, interventional studies, interviews, or news reports

c. Measurements: non-validated mental health instruments (i.e., self-made questionnaire) or instruments without a validated cutoff score to calculate a prevalence rate (i.e., STAI, SCL-90 for anxiety and depression).

We contacted the authors of papers that missed some critical information if the articles:

a. Contain primary data on mental health of relevant population using established instruments under COVID-19 period but do not report the prevalence rates. For example, a study may report the mean and SD of our outcomes but not their prevalence rates.

b. Surveyed a sample that mixed our targeted population and other populations, such as children, in a manner such that we could not extract the prevalence rate(s) for our targeted population. We included the studies that authors provided prevalence rate for our targeted population only and excluded the studies with mixed populations.

c. Miss some critical information, such as the data collection time or location.

d. Are unclear on critical information. For example, some articles are unclear whether they used the cutoff for mild or moderate symptoms to calculate the overall prevalence rates of mental issues.

\subsection{Selection Process and Data Extraction}

The articles that passed the inclusion criteria were exported into an EndNote library where we identified duplications and then imported to Rayyan for screening. Two researchers 
(L.T. and Y.Y.) independently screened the articles based on their titles and abstracts. If both coders excluded an article independently, it was excluded.

Six researchers (X.C, M.Z., R.C., Z.D., R.D., B.C.) were paired to assess the eligibility of each paper based on reading its full text and extracting the relevant data into a coding book based on a coding protocol. The coding book records information such as the authors and year of the paper, title, publication status, sample locations, date of data collection, sample size, response rate, population, age (mean, SD, min and max), gender proportion, instruments, cutoff scores used, the prevalence/mean/SD of the mental health outcome, and other notes or comments. Pairs of researchers first double-coded and crosschecked each paper independently. The remaining discrepancies after the crosscheck were discussed between the pair of coders. In cases where a pair of coders continued to disagree, a lead coder (X.C.) checked the paper independently and discussed it with the two original coders to determine its coding. The lead coder also integrated and reviewed all the coding information. Particularly, the lead coder checked the mental outcomes, instruments, outcome levels, and cutoff scores reported given the multitude of reporting practices in individual papers. We were able to identify papers that used unusual cutoff scores later for sensitivity analysis.

\subsection{Assessment of Bias Risk}

Following other meta-analyses (de Pablo et al., 2020; Usher et al., 2020), we used the Mixed Methods Appraisal Tool (MMAT) (Hong et al., 2018), including seven questions to conduct the quality assessment of the studies. Pairs of coders independently evaluated the risk of bias and quality of the studies and rated them based on the MMAT. Most discrepancies were resolved through a discussion between the pair of researchers, and any disagreement after discussions was resolved by a lead researcher. Papers were classed into high (6 - 7) or medium quality (lower than 6). 
medRxiv preprint doi: https://doi.org/10.1101/2021.02.01.21250929; this version posted April 30, 2021. The copyright holder for this preprint

\subsection{Statistical Analysis}

To analyze the data in a consistent manner, we ensure the independence of mental health disorders and samples. For instance, for studies that examine a mental health outcome with more than one instrument, we report the results based on the most popular instrument. If a study reported several prevalence rates by several cutoffs, we use one of them, in the following order of preference: above the severe cutoff, above the moderate cutoff, and above the mild cutoff. Thus, only one prevalence rate for a mental health outcome in a population is entered into the meta-analysis to ensure the samples remain independent.

The overall prevalence and $95 \%$ confidence intervals of psychological outcomes were pooled using Stata 16.1. Similar to prior studies on the prevalence of mental issues, the random-effects model was used to extract the pooled estimates (DerSimonian and Laird, 1986). We reported the heterogeneity by the $I^{2}$ statistic, which measures the percentage of variance resulting from true differences in the effect sizes rather than the sampling error (Higgins et al., 2019). We performed subgroup analyses by the key potential sources of heterogeneity of outcomes (six types of mental health disorders), severity of outcome (above mild/above moderate/above severe), and three major population groups (frontline HCWs, general HCWs, general population). Furthermore, given the high degree of heterogeneity of the true differences in the effect sizes, we ran a meta-regression to regress the prevalence upon not only these three category variables (outcome, severity, and population) but also female proportion, data collection time, data collection location (Wuhan vs. non-Wuhan), sample size, and study quality. We included data collection time to examine whether the mental issues change over time dynamically. While the COVID-19 crisis continues to evolve, there is a lack of dynamic analysis on the mental disorders of any population over time. Sensitivity analysis was conducted, and Funnel plots were used to assess publication bias. Significance level was set as two-sided and $\mathrm{p}<0.05$. 
medRxiv preprint doi: https://doi.org/10.1101/2021.02.01.21250929; this version posted April 30, 2021. The copyright holder for this preprint (which was not certified by peer review) is the author/funder, who has granted medRxiv a license to display the preprint in perpetuity.

\section{RESULTS}

\subsection{Study Screening}

Our systematic search (Figure 1) across all the databases yielded 5431 potentially relevant papers, out of which 2365 were duplications and removed. Of the remaining 3066 papers, we screened their titles and abstracts in the first stage and the full text of the 445 articles in the second stage. We also emailed the authors of 43 articles that missed critical information and were able to get the information to include 10 additional studies. Altogether, the process generated 131 articles for this meta-analysis (An et al., 2020; Ben-Ezra et al.; Cai et al.; Cao et al., 2020; Chen et al.; Chen et al.; Chen et al.; Chen et al.; Chen et al., 2020; Cheng et al.; Choi et al.; Dai, 2020; Dong et al., 2020; Du et al., 2020; Elhai et al., 2020; Fang et al., 2020; Feng et al., 2020; Fong et al., 2020; Fu et al., 2020; Gao, 2020; Guo, 2020; Guo et al., 2020; Han et al., 2020; Hong et al., 2020; Hou et al., 2020; Hu et al., 2020a; Hu et al., 2020b; Huang et al., 2020a; Huang et al., 2020c; Huang et al., 2020d; Jin et al., 2020; Juan et al., 2020; Lai et al., 2020; Lam et al., 2020; Lei et al., 2020; Leng et al., 2020; Li; Li et al., 2020a; Li et al., 2020b; Li et al., 2020c; Li, 2020a; Li et al., 2020d; Li, 2020b; Li et al., 2020e; Li et al., 2020f; Li et al., 2020g; Liang et al., 2020; Lin et al., 2020a; Lin et al., 2020b; Liu, 2020; Liu, in press; Liu et al., 2020a; Liu et al., 2020b; Liu et al., 2020c; Liu et al., 2020d; Liu et al., 2020e; Liu et al., 2020f; Lu et al., 2020a; Lu et al., 2020b; Lu et al., 2020c; Mi et al., 2020; Ni et al., 2020a; Ni et al., 2020b; Ning et al., 2020; Pan et al., 2020a; Pan et al., 2020b; Qi, 2020; Qian, 2020; Qian et al., 2020; Qiu et al., 2020; Que et al., 2020; Ren et al., 2020b; Shi et al., 2020; Si et al., 2020; Song et al., 2020; Song, 2020; Su et al., 2020; Sun et al., 2020a; Sun, 2020; Sun et al., 2020b; Sun et al., 2020c; Tan et al., 2020; Teng et al., 2020; Tu et al., 2020; Wang et al., 2020a; Wang et al., 2020b; Wang et al., 2020c; Wang et al., 2020d; Wang et al., 2020e; Wang et al., 2020f; Wang et al., 2020g; Wang et al., 2020h; Wang et al., 2020i; Wang et al., 2020j; Wu et al., 2020a; Wu et al., 2020b; Wu et al., 2020c; 
medRxiv preprint doi: https://doi.org/10.1101/2021.02.01.21250929; this version posted April 30, 2021. The copyright holder for this preprint (which was not certified by peer review) is the author/funder, who has granted medRxiv a license to display the preprint in perpetuity. It is made available under a CC-BY-ND 4.0 International license .

Xiao et al., 2020; Xiaoming et al., 2020; Xing et al., 2020; Xiong et al., 2020; Xu et al., 2020; Yang et al., 2020a; Yang et al., 2020b; Yin et al., 2020; Yin et al.; Ying et al., 2020; Yu et al., 2020a; Yu et al., 2020b; Zhan et al., 2020a; Zhan et al., 2020b; Zhang et al., 2020a; Zhang et al., 2020b; Zhang et al., 2020c; Zhang, 2020; Zhang et al., 2020f; Zhang et al., 2020i; Zhang et al., 2020j; Zhang et al., 2020k; Zhang and Ma, 2020; Zhang et al., 2020m; Zhao et al., 2020a; Zhao et al., 2020b; Zhao et al., 2020c; Zhou et al., 2020a; Zhou et al., 2020b; Zhou et al., 2020c; Zhu et al., 2020a; Zhu et al., 2020b; Zhu et al., 2020c; Zhu, 2020).

\subsection{Study Characteristics}

The 131 papers included contains 171 samples (Table S2) with a total of 630,244 individual participants. Table 1 summarizes their key characteristics. Among the 171 independent samples, about a quarter of them studied frontline HCWs and general HCWs (27.5\% and $26.9 \%$, respectively), and almost half studied the general population $(45.6 \%)$. More than one-third of samples covered anxiety and depression. Another one-third investigated other mental issues including insomnia, PTSD, distress, and general psychological symptoms (GPS) $(15.0 \%, 8.4 \%, 2.5 \%$, and $2.0 \%$, respectively). Respectively, $23.7 \%, 46.4 \%$, and $29.9 \%$ of samples reported prevalence rates at the mild above, moderate above, and severe above level by the severity of the symptoms.

Almost all the studies, 126 out of 131, employed cross-sectional surveys; specifically, $9(6.9 \%)$ conducted the survey in January 2020, 85 (64.9\%) in February, 23 (17.6\%) in March, and 14 (10.6\%) in April or later. Almost one-quarter of them (22.2\%) contained a sample targeting populations in Wuhan. Most studies were published in journals, and 10 (7.6\%) studies remained as preprints. The assessment based on the Mixed Methods Appraisal Tool (MMAT) indicated $100(73.3 \%)$ studies were of good quality (score no less than 6 out of 7) and 31 studies were of medium quality (score less than 6 but greater than 4 ). The median number of individuals per sample was 709 (range: 30 to 123,768) with a median 
medRxiv preprint doi: https://doi.org/10.1101/2021.02.01.21250929; this version posted April 30, 2021. The copyright holder for this preprint

female proportion of $69 \%$ (range: $12 \%$ to $100 \%$ ) and a median response rate of 5\% (range: $14 \%$ to $100 \%)$.

The 131 papers employed a wide arrange of instruments to assess mental health (Table S3). For both anxiety and depression, PHQ $(60.6 \%, 63.3 \%)$ and SAS $(23.6 \%, 13.3 \%)$ are the first and second most popular measures; distress is measured the most by K6 (44.4\%), followed by IES-R (22.2\%); insomnia is measured by ISI (63.2\%) and PSQI (29.8\%); PTSD by IES-R (40.0\%), PCL-C (26.7\%), and PCL-5 (26.7\%); and general psychological symptoms by SRQ-20 (100.0\%). Please see the details in Table S3.

\subsection{Major Issues from Findings of the Key Study Characteristics}

Our systematic review reveals several widespread issues in mental health research during COVID-19: a wide array of instruments, inconsistent reporting of prevalence rates, inconsistent use and reporting of cutoff points, different cutoff values to determine the overall prevalence as well as the severity, and other issues on reporting standards and terminologies.

A myriad of instruments. The individual papers on mental health research during COVID-19 employed a wide variety of instruments with varying degrees of popularity and validity (summarized in Table S3). The wide array of instruments, especially the use of less frequently used instruments (i.e., AIS, BAI/BDI), certainly has some benefit but makes it hard to make comparisons or accumulate evidence.

Admixed outcome severity level. The individual papers reported the prevalence rates at a range of severity of the symptoms. First, the articles differ in their terminology when reporting the overall prevalence rates. Some papers used the overall prevalence rate to indicate the percentage with moderate symptoms or above, other papers used it to indicate the percentage with mild symptoms or above e.g., (Du et al., 2020) (Zhang et al., 2020b). Even worse, a large number of papers did not specify the definition of the overall prevalence rate, rendering it impossible to know whether it refers to above mild or moderate levels. Second, some papers 
medRxiv preprint doi: https://doi.org/10.1101/2021.02.01.21250929; this version posted April 30, 2021. The copyright holder for this preprint

use other terminologies, such as "extremely severe" (Ozamiz-Etxebarria et al., 2020), "very severe” (Moghanibashi-Mansourieh, 2020), or “very high” (Temsah, 2020), “moderatesevere" e.g., (Guiroy et al., 2020), "moderate to severe" (Moccia et al., 2020; Wang et al., 2020a), "moderately severe" e.g., (Xiaoming et al., 2020), and "poor" (Wang et al., 2020f), which often is not clear in terms of the cutoff points used to categorize those symptoms. We opted to recode all the papers that indicate their cutoff scores manually(Antony et al., 1998; Beusenberg et al., 1994; Blevins et al., 2015; Buysse et al., 1989; Cheng et al., 2002; Cheung et al., 2007; Creamer et al., 2003; Dai, 2020; Dobie et al., 2002; Guo et al., 2017; Health; Kessler et al., 2010; Kroenke et al., 2001; Kroenke et al., 2009; Lee et al., 2018; Matza et al., 2010; Morin et al., 2011; Prins et al., 2016; Qiu et al., 2020; Schlenger et al., 2002; Soldatos et al., 2000; Spitzer et al., 2006; Thoresen et al., 2010; Tsai et al., 2005; Wang et al., 2017; Wang et al., 2011; Wilberforce et al., 2010; Wu et al., 2003; Zigmond and Snaith, 1983;

Zimmerman et al., 2013; Zung, 1965, 1971; 王春芳 et al., 1986); however, these

terminologies may contribute to the heterogeneity and confusion in accumulating evidence.

Clarity on the cutoff points used to determine severity. Some papers employed

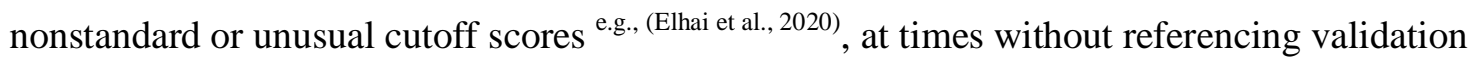
studies that supported the use of those special cutoff scores ${ }^{\text {e.g., (Cai et al.; Song et al., 2020) }}$. Some papers did not report the cutoff score used or provide any references e.g., (Cao et al., 2020; Sun et al., 2020b) , making the assessment difficult. Such issues seem to occur particularly in studies that used PSQI, IES-R and DASS-21, and CES-D.

\subsection{Pooled Prevalence Rates of Mental Health Disorders}

The prevalence rates of the 171 samples were pooled by the subgroups (Table 2). First, the overall prevalence rates of mental health disorders that surpassed the cutoff values of mild, moderate, and severe symptoms were $27 \%, 18 \%$, and $3 \%$, respectively. The overall prevalence of mental health disorder frontline $\mathrm{HCWs}$, general $\mathrm{HCWs}$, and the general 
medRxiv preprint doi: https://doi.org/10.1101/2021.02.01.21250929; this version posted April 30, 2021. The copyright holder for this preprint

population in China are 17\%, 14\%, and $12 \%$, respectively. The overall prevalence of anxiety, depression, distress, GPS, insomnia, and PTSD are 11\%, 13\%, 20\%, 13\%, 19\%, and $20 \%$. Figure 2 graphically depicts such findings of the pooled analysis by subgroups using forest plots.

\subsection{Meta-regression on the Prevalence of Mental Health Disorders}

To better explain the heterogeneity of the prevalence of mental health disorders, Table 3 reports the results of a meta-regression analysis. The meta-analytical model explained over $40 \%$ of the variance of mental health disorders among these studies $\left(R\right.$-squared $=41.0 \%, I^{2}=$ $\left.100 \%, \operatorname{tau}^{2}=0.11\right)$. The prevalence of severe mental health disorders is significantly lower than that of moderate mental illness $(p<0.01)$, which is in turn significantly lower than those of mild mental illness $(p<0.01)$. The prevalence of mental health disorders of frontline HCWs is significantly higher than that of general HCWs $(p<0.004)$. General HCWs and the general population do not differ in their mental health prevalence rates. The prevalence rates of depression $(p=0.04)$ and insomnia $(p=0.04)$ are significantly higher than that of anxiety, and the rates of general psychological symptoms $(p=0.20)$ and PTSD $(p=0.20)$ do not differ significantly from that of anxiety. Interestingly, the prevalence of mental health disorders of participants in Wuhan, the epicenter of the COVID-19 crisis, was significantly lower than that in non-Wuhan samples in China $(p=0.04)$. The prevalence rates of mental health disorders were higher in studies of papers with a higher quality rating $(p=0.03)$. The female proportion $(p=0.54)$, date of data collection $(p=0.64)$, sample size of studies $(p=0.16)$, or publication status $(p=0.80)$ did not predict the prevalence rates significantly.

The meta-analytical results enable the prediction of prevalence rates while taking account of the influence of multiple factors and hence offer a superior model over the earlier pooled analyses. In other words, the meta-regression model considers multiple predictors of mental health disorders in a single model at the same time instead of the approach of 
considering one predictor at a time by pooled prevalence, the typical method to estimate the prevalence of mental health disorder in prior meta-analytical papers in COVID-19 literature. Hence, based on the results of the meta-regression, we report the predicted prevalence rates of varying severity levels of the symptoms of different mental health disorders of frontline HCWs, general HCWs, and the general population. Table 4 and Figure 3 show the predicted prevalence rates of mental health disorders by populations, outcomes, and severity by the meta-analytical regression model. As illustrated in Figure 3, the prevalence rates vary greatly by the mental health outcomes and severity. The prevalence rates are lower when using a higher level of severity, which drives the heterogeneity of prevalence rate to a large degree. Among the different types of mental health outcomes, distress seems to be the most prevalent among all three populations.

\subsection{Sensitivity Analysis}

Our meta-analytical model was able to take account of the impact of several factors, such as publication status (insignificant), sample size (insignificant), and article quality score (significant). Furthermore, we conducted our analysis with the exclusion of each study oneby-one from the meta-analytic model and found it did not significantly alter the findings. The visual inspection of the sensitivity plot however revealed that there is significant asymmetry. Figure 4 reports the DOI plot in combination with the Luis-Kanamori (LFK) index, which has higher sensitivity and power than a funnel plot (Mboua et al., 2020; Teshome et al., 2020). An LFK index scores of \pm 1 , between \pm 1 and \pm 2 , or \pm 2 indicating 'no asymmetry', 'minor asymmetry', and 'major asymmetry' respectively, and hence the LFK index of 2.1 represents major asymmetry. Therefore, the presence of publication bias is likely.

\section{DISCUSSION}

\subsection{Comparison with Prior Meta-analyses}


medRxiv preprint doi: https://doi.org/10.1101/2021.02.01.21250929; this version posted April 30, 2021. The copyright holder for this preprint

The meta-analysis of mental health one year into the COVID-19 epidemic in China revealed several findings that are worth comparing with prior meta-analyses on the same topic. See Table 5 for a summary of the comparison.

Unlike prior meta-analyses, most of which searched the literature before May 2020, our meta-analysis covered a whole year of COVID-19 to yield stronger evidence. Our metaanalysis from a systematic review comprises 171 independent samples with 630,244 participants from 131 studies, much larger than the prior meta-analyses on China's population that included 7-50 studies with 2123 to 62,382 participants (Bareeqa et al., 2020; Krishnamoorthy et al., 2020; Pappa, 2020; Ren et al., 2020a; Salari et al., 2020b). The comparison reveals that our pooled prevalence rates largely fall between the findings of previous meta-analyses, suggesting our larger data is consistent yet fine-tunes them. For example, we reported a higher prevalence of anxiety for the general population and HCWs (24\%) than Bareeqa et al. (2020) (22\%) and Pappa et al. (2020) (23\%), but lower than Krishnamoorthy et al. 2020 (26\%) and Ren et al. 2020 (25\%). Similarly, we reported a higher prevalence of anxiety for frontline HCWs (28\%) than Bareeqa et al. (2020) (24\%) and a lower prevalence of depression (25\%) for the general population and HCWs than the prevalent rates of $26 \%$ - 28\% in Ren et al. 2020, Krishnamoorthy et al. 2020, and Bareeqa et al. 2020. All these differences between our prevalence rates and the prior reports (Bareeqa et al., 2020; Krishnamoorthy et al., 2020; Pappa, 2020; Ren et al., 2020a) are statistically significant due to the large sample size involved, and hence we significantly update the cumulative evidence on mental health prevalence rates in COVID-19. Our findings also suggest a need to update meta-analyses continuously to provide more accurate estimates of the prevalence of mental illness while COVID-19 is ongoing.

Our systematic review over a year of the COVID-19 crisis allows us to identify all the major mental health outcomes studied (anxiety, depression, insomnia, GPS, distress, and 
PTSD). In particular, GPS has never been included in any prior meta-analysis. Moreover, prior meta-analyses examined the prevalence rates of mental health disorders based on one level of the severity of symptoms (i.e., above mild), and we included articles that reported the prevalence at varying levels of severity of symptoms.

\subsection{Meta-regression Findings}

Thanks to the large number of samples in China over a year of the COVID-19 crisis, we were able to conduct meta-regression to account for the influence of multiple predictors at the same time to enable better prediction on the prevalence of each mental health disorder. The accumulative evidence shows that several predictors are significantly associated with prevalence rates of mental issues in China during COVID-19, including the severity and type of mental issues, population, sampling location, and study quality.

The severity of mental symptoms, which has been unaccounted for in prior metaanalyses, was found to contribute greatly to the heterogeneity of prevalence rates, hence individual mental health papers need to pay special attention to the severity with clarity. Otherwise, researchers and practitioners might mix the severity of severe, moderate, and mild mental illness. Since prior meta-analyses largely examined the prevalence rates of mild mental health disorders, yet psychiatrists care not only the mild symptoms, and the significant differences revealed by this study call for more meta-analyses on varying levels of severity to provide evidence for practitioners relevant to their concerns.

Among the six types of mental health issues examined, distress and insomnia had the highest prevalence rates among all three populations. Our findings suggest that practitioners need to be aware and pay more attention to distress and insomnia under the COVID-19 pandemic. Moreover, given that more than two-thirds of existing empirical studies focused on anxiety and depression, we call out for future research to focus on mental distress and insomnia. 
Frontline HCWs suffered more than general HCWs and the general population across all six types of mental issues. It is also worth noting the general HCWs did not significantly differ from general populations across any mental issues. Hence, our evidence suggests that policymakers and healthcare organizations need to further prioritize frontline HCWs the most in this ongoing pandemic.

Past mental health research has reported inconsistent results on the relationship between individuals' mental issues and their locations. Some studies reported that mental issues increase along with the distance to the epicenter in the COVID-19 pandemic, known as "typhoon eye effect" (Tang et al., 2020; Zhang et al., 2020d; Zhang et al.). However, other findings have demonstrated an opposite effect, where mental issues decrease as the distance to the epicenter increases, known as the "ripple effect" (Huang et al., 2020b; Zhang et al., 20201). Our accumulative evidence shows that people in the epicenter of China in Wuhan suffered less mental issues than those outside of Wuhan, lending support to the typhoon eye effect. This finding suggests future research to differentiate, report, and possibly model sampling locations based on the epicenter of a pandemic to enable better geographical identification of mental issues (Yáñez, 2020; Zhang et al., 2020e; Zhang et al., 2020g).

Our findings that the samples in papers with higher quality tend to find higher prevalent rates of mental issues suggest study quality may matter. Particularly, future metaanalysis may pay attention to the representativeness of sampling, the response rate, etc., to better account for the heterogeneity in the pooled prevalence rates.

As the COVID-19 epidemic evolves, we expected the mental issues may change over time. However, the evidence of meta-regression using time as a predictor failed to reveal significant effect, even though the COVID crisis has evolved to varying degrees for more than a year in countries such as China. A potential reason might be the development of 
COVID-19 in various parts of China happened at varying paces, and more refined studies are needed to uncover the change of prevalence rates effect over time.

\subsection{A Mental Health Research Agenda during Covid-19}

Our systemic review and meta-analysis allowed us to observe several widespread problems in the individual papers that impede the accumulation of evidence. We offer a few concrete suggestions on research focus and reporting for future mental health studies for authors, editors, and reviewers in a table for easy reference (Table 6) to improve the quality of such studies and to facilitate evidence accumulation in future meta-analyses.

\subsection{Study Limitations}

This meta-analysis has a few limitations. First, the validity of our findings rests upon the quality and reporting of the original studies. As discussed before, individual mental health papers varied in their usage of instruments, cutoff scores, the use of cutoff scores to define mental issues, and the reporting standards. For example, the overall prevalence refers to "above the cutoff of mild" in some papers yet "above the cutoff of moderate" in other papers. Worse, many papers report the overall prevalence without specifying which/how cutoff scores are used. While we paid extra attention to the severity, the cutoff points, and the ways in which individual articles used this information, the multitude of varying practices contributes to additional noise and variance in the analysis. Second, since we included studies in English, which may result in some biases. Third, $96.2 \%$ of studies included in this metaanalysis were cross-sectional surveys, and we call for more cohort studies to examine the effect of time. Finally, we only focus on studies that collected data in China, and we call for future meta-analyses in other countries or regions as the COVID-19 crisis continues in most parts of the world.

\subsection{Conclusion}


Since the COVID-19 epidemic started in November 2019, hundreds of studies have documented the mental health of major populations by the key mental outcomes and varying levels of severity. This systematic review and meta-analysis synthesized the evidence on the prevalence rates of mental health disorders in China over one year of the COVID-19 epidemic. The meta-regression results provide evidence that future research should pay attention to mental distress and insomnia, especially given the popularity of anxiety and depression in the literature to date. Moreover, we revealed a number of issues in the individual papers published on mental health during the COVID-19 crisis, and the high heterogeneity among studies calls for more standard reporting of future research not only during COVID-19 but also generally to better facilitate the synthesis of evidence to enable evidence-based research and practice. 
medRxiv preprint doi: https://doi.org/10.1101/2021.02.01.21250929; this version posted April 30, 2021. The copyright holder for this preprint

(which was not certified by peer review) is the author/funder, who has granted medRxiv a license to display the preprint in perpetuity.

It is made available under a CC-BY-ND 4.0 International license .

\section{Competing interest statement}

All authors have completed the Unified Competing Interest form and declare: no support from any organisation for the submitted work; no financial relationships with any

organisations that might have an interest in the submitted work in the previous three years, no other relationships or activities that could appear to have influenced the submitted work.

\section{Credit author statement}

XC: Investigation, Data curation, Visualization, Writing - original draft, Writing - review \& editing, Project administration. JC: Conceptualization, Methodology, Validation, Formal analysis, Investigation, Resources, Data curation, Visualization, Writing - original draft, Writing - review \& editing, Supervision. MZ, RC, RD, ZD, YY, BC, LT: Investigation (Data). RZ, WC, PL: Investigation. SZ: Conceptualization, Methodology, Validation, Formal analysis, Investigation, Data curation, Writing - original draft, Writing - review \& editing, Supervision. XC, JC, and SZ co-lead this project. All authors were involved in approving the manuscript. The corresponding author attests that all listed authors meet authorship criteria and that no others meeting the criteria have been omitted.

\section{Transparency declaration}

The lead author* affirms that this manuscript is an honest, accurate, and transparent account of the study being reported; that no important aspects of the study have been omitted; and that any discrepancies from the study as planned (and, if relevant, registered) have been explained.

\section{Ethical approval}

Not applicable 
medRxiv preprint doi: https://doi.org/10.1101/2021.02.01.21250929; this version posted April 30, 2021. The copyright holder for this preprint (which was not certified by peer review) is the author/funder, who has granted medRxiv a license to display the preprint in perpetuity.

It is made available under a CC-BY-ND 4.0 International license .

\section{Funding sources/sponsors}

Not applicable

\section{Patient and public involvement}

No patient or public was involved in a systematic review and meta-analysis

\section{Acknowledgements}

We thank Haixing Zheng, Shaokun Xu, Fei Liang \& Zhehong Xu for their help.

\section{Data sharing statement}

All data generated or analyzed during this study are included in this published article. 


\section{References}

An, Y., Yang, Y., Wang, A., Li, Y., Zhang, Q., Cheung, T., Ungvari, G.S., Qin, M.Z., An, F.R., Xiang, Y.T., 2020. Prevalence of depression and its impact on quality of life among frontline nurses in emergency departments during the COVID-19 outbreak. J Affect Disord 276, 312-315.

Antony, M.M., Bieling, P.J., Cox, B.J., Enns, M.W., Swinson, R., 1998. Psychometric properties of the 42-item and 21-item versions of the Depression Anxiety Stress Scales in clinical groups and a community sample. Psychological assessment 10 (2), 176.

Bareeqa, S.B., Ahmed, S.I., Samar, S.S., Yasin, W., Zehra, S., Monese, G.M., Gouthro, R.V., 2020. Prevalence of depression, anxiety and stress in china during COVID-19 pandemic: A systematic review with meta-analysis. The International Journal of Psychiatry in Medicine, 0091217420978005.

Ben-Ezra, M., Sun, S., Hou, W.K., Goodwin, R., The association of being in quarantine and related COVID-19 recommended and non-recommended behaviors with psychological distress in Chinese population. 275, 66-68.

Beusenberg, M., Orley, J.H., World Health Organization. Division of Mental, H., 1994. A User's guide to the self reporting questionnaire (SRQ / compiled by M. Beusenberg and J. Orley. World Health Organization, Geneva.

Blevins, C.A., Weathers, F.W., Davis, M.T., Witte, T.K., Domino, J.L.J.J.o.t.s., 2015. The posttraumatic stress disorder checklist for DSM $\square 5$ (PCL $\square$ 5): Development and initial psychometric evaluation. 28 (6), 489-498.

Bryner, J., March 14, 2020. 1st known case of coronavirus traced back to November in China.

Buysse, D.J., Reynolds III, C.F., Monk, T.H., Berman, S.R., Kupfer, D.J.J.P.r., 1989. The Pittsburgh Sleep Quality Index: a new instrument for psychiatric practice and research. 28 (2), 193-213.

Cai, Z., Cui, Q., Liu, Z., Li, J., Gong, X., Liu, J., Wan, Z., Yuan, X., Li, X., Chen, C., Wang, G., Nurses endured high risks of psychological problems under the epidemic of COVID-19 in a longitudinal study in Wuhan China. 131, 132-137.

Cao, J., Wei, J., Zhu, H., Duan, Y., Geng, W., Hong, X., Jiang, J., Zhao, X., Zhu, B., 2020. A Study of Basic Needs and Psychological Wellbeing of Medical Workers in the Fever Clinic of a Tertiary General Hospital in Beijing during the COVID-19 Outbreak. Psychother Psychosom 89 (4), 252-254.

Chen, B., Li, Q.X., Zhang, H., Zhu, J.Y., Yang, X., Wu, Y.H., Xiong, J., Li, F., Wang, H., Chen, Z.T., The psychological impact of COVID-19 outbreak on medical staff and the general public. 1-9.

Chen, H., Wang, B., Cheng, Y., Muhammad, B., Li, S., Miao, Z., Wan, B., Abdul, M., Zhao, Z., Geng, D., Xu, X., Prevalence of posttraumatic stress symptoms in health care workers after exposure to patients with COVID-19. 13, 100261.

Chen, H., Zhao, X., Zeng, M., Li, J., Ren, X., Zhang, M., Liu, Y., Yang, J., Collective selfesteem and perceived stress among the non-infected general public in China during the 2019 coronavirus pandemic: A multiple mediation model. 168, 110308.

Chen, J., Liu, X., Wang, D., Jin, Y., He, M., Ma, Y., Zhao, X., Song, S., Zhang, L., Xiang, X., Yang, L., Song, J., Bai, T., Hou, X., Risk factors for depression and anxiety in healthcare workers deployed during the COVID-19 outbreak in China. 10, 10.

Chen, Y., Zhou, H., Zhou, Y., Zhou, F., 2020. Prevalence of self-reported depression and anxiety among pediatric medical staff members during the COVID-19 outbreak in Guiyang, China. Psychiatry Res 288, 113005. 
Cheng, F.F., Zhan, S.H., Xie, A.W., Cai, S.Z., Hui, L., Kong, X.X., Tian, J.M., Yan, W.H., Anxiety in Chinese pediatric medical staff during the outbreak of Coronavirus Disease 2019: a cross-sectional study. 9 (3), 231-236.

Cheng, S.K.-W., Wong, C.-W., Wong, K.-C., Chong, G.S.-C., Wong, M.T.-P., Chang, S.S.Y., Wong, S.-Y., Chan, C.K.-Y., Wu, K.-O., 2002. A study of psychometric properties, normative scores, and factor structure of the Beck Anxiety Inventory--the Chinese version. Chinese Journal of Clinical Psychology.

Cheung, Y.B., Liu, K.Y., Yip, P.S.J.S., 2007. Performance of the CES-D and its short forms in screening suicidality and hopelessness in the community. Suicide and LifeThreatening Behavior 37 (1), 79-88.

Choi, E.P.H., Hui, B.P.H., Wan, E.Y.F., Depression and Anxiety in Hong Kong during COVID-19. 17 (10), 25.

Creamer, M., Bell, R., Failla, S.J.B.r., therapy, 2003. Psychometric properties of the impact of event scale-revised. 41 (12), 1489-1496.

Dai, Y., Hu, G., Xiong, H., Qiu, H., \& Yuan, X., 2020. Psychological impact of the coronavirus disease 2019 (COVID-19) outbreak on healthcare workers in China.

de Pablo, G.S., Serrano, J.V., Catalan, A., Arango, C., Moreno, C., Ferre, F., Shin, J.I., Sullivan, S., Brondino, N., Solmi, M., 2020. Impact of coronavirus syndromes on physical and mental health of health care workers: Systematic review and metaanalysis. Journal of affective disorders.

DerSimonian, R., Laird, N., 1986. Meta-analysis in clinical trials. Controlled clinical trials 7 (3), 177-188.

Dobie, D.J., Kivlahan, D.R., Maynard, C., Bush, K.R., McFall, M., Epler, A.J., Bradley, K.A.J.G.h.p., 2002. Screening for post-traumatic stress disorder in female Veteran's Affairs patients: validation of the PTSD checklist. 24 (6), 367-374.

Dong, Z.-Q., Ma, J., Hao, Y.-N., Shen, X.-L., Liu, F., Gao, Y., Zhang, L.J.E.P., 2020. The social psychological impact of the COVID-19 pandemic on medical staff in China: A cross-sectional study. 63 (1).

Douglas, M., Katikireddi, S.V., Taulbut, M., McKee, M., McCartney, G.J.B., 2020. Mitigating the wider health effects of covid-19 pandemic response. BMJ 369.

Du, J., Dong, L., Wang, T., Yuan, C., Fu, R., Zhang, L., Liu, B., Zhang, M., Yin, Y., Qin, J., Bouey, J., Zhao, M., Li, X., 2020. Psychological symptoms among frontline healthcare workers during COVID-19 outbreak in Wuhan. Gen Hosp Psychiatry.

Elhai, J.D., Yang, H., McKay, D., Asmundson, G.J.J.J.o.A.D., 2020. COVID-19 anxiety symptoms associated with problematic smartphone use severity in Chinese adults.

Fang, X., Zhang, J., Teng, C., Zhao, K., Su, K.-P., Wang, Z., Tang, W., Zhang, C.J.J.o.a.d., 2020. Depressive symptoms in the front-line non-medical workers during the COVID-19 outbreak in Wuhan. 276, 441-445.

Feng, Z., Xu, L., Cheng, P., Zhang, L., Li, L.-J., Li, W.-H.J.I.j.o.p., 2020. The psychological impact of COVID-19 on the families of first-line rescuers. 62 (Suppl 3), S438.

Fong, B.Y., Wong, M., Law, V.T., Lo, M.F., Ng, T.K., Yee, H.H., Leung, T.C., Ho, P.W.J.I.J.o.E.R., Health, P., 2020. Relationships between Physical and Social Behavioural Changes and the Mental Status of Homebound Residents in Hong Kong during the COVID-19 Pandemic. 17 (18), 6653.

Fu, W., Wang, C., Zou, L., Guo, Y., Lu, Z., Yan, S., Mao, J.J.T.p., 2020. Psychological health, sleep quality, and coping styles to stress facing the COVID-19 in Wuhan, China. 10 (1), 1-9.

Gao, J., Zheng, P., Jia, Y., Chen, H., Mao, Y., Chen, S., . . Dai, J., 2020. Mental health problems and social media exposure during COVID-19 outbreak. PLoS ONE 15 (4), e0231924. 
Guiroy, A., Gagliardi, M., Coombes, N., Landriel, F., Zanardi, C., Camino Willhuber, G., Guyot, J.P., Valacco, M., 2020. COVID-19 Impact Among Spine Surgeons in Latin America. Global Spine J, 2192568220928032.

Guo, J., Feng, X.L., Wang, X.H., van IJzendoorn, M.H.J.I.J.o.E.R., Health, P., 2020. Coping with COVID-19: Exposure to COVID-19 and Negative Impact on Livelihood Predict Elevated Mental Health Problems in Chinese Adults. 17 (11), 3857.

Guo, J., He, H., Fu, M., Han, Z., Qu, Z., Wang, X., Guan, L.J.P.r., 2017. Suicidality associated with PTSD, depression, and disaster recovery status among adult survivors 8 years after the 2008 Wenchuan earthquake in China. 253, 383-390.

Guo, J., Liao, L., Wang, B., Li, X., Guo, L., Tong, Z., ... Gu, Y., 2020. Psychological effects of COVID-19 on hospital staff: a national cross-sectional survey of China mainland.

Han, L., Wong, F.K.Y., She, D.L.M., Li, S.Y., Yang, Y.F., Jiang, M.Y., Ruan, Y., Su, Q., Ma, Y., Chung, L.Y.F., 2020. Anxiety and Depression of Nurses in a North West Province in China During the Period of Novel Coronavirus Pneumonia Outbreak. J Nurs Scholarsh.

Health, W.C.C.i.M., Chinese version of the WHO-Five Well-Being Index.

Higgins, J.P., Thomas, J., Chandler, J., Cumpston, M., Li, T., Page, M.J., Welch, V.A., 2019. Cochrane handbook for systematic reviews of interventions. John Wiley \& Sons.

Hong, Q.N., Pluye, P., Fàbregues, S., Bartlett, G., Boardman, F., Cargo, M., Dagenais, P., Gagnon, M.-P., Griffiths, F., Nicolau, B., 2018. Mixed methods appraisal tool (MMAT), version 2018. Registration of copyright 1148552, 10.

Hong, S., Ai, M., Xu, X., Wang, W., Chen, J., Zhang, Q., Wang, L., Kuang, L.J.N.o., 2020. Immediate psychological impact on nurses working at 42 government-designated hospitals during COVID-19 outbreak in China: A cross-sectional study.

Hou, F., Bi, F., Jiao, R., Luo, D., Song, K.J.B.p.h., 2020. Gender differences of depression and anxiety among social media users during the COVID-19 outbreak in China: a cross-sectional study. 20 (1), 1-11.

Hu, D., Kong, Y., Li, W., Han, Q., Zhang, X., Zhu, L.X., Wan, S.W., Liu, Z., Shen, Q., Yang, J.J.A., Depression,, Statuses, F., Their Associated Factors During the COVID-19 Outbreak in Wuhan, C.A.B.-S.C.-S.S., 2020a. Frontline Nurses' Burnout, Anxiety, Depression, and Fear Statuses and Their Associated Factors During the COVID-19 Outbreak in Wuhan, China: A Big-Scale Cross-Sectional Study.

Hu, N., Li, Y., He, S.-S., Wang, L.-L., Wei, Y.-Y., Yin, L., Chen, J.-X.J.F.i.P., 2020b. Impact of the Family Environment on the Emotional State of Medical Staff During the COVID-19 Outbreak: The Mediating Effect of Self-Efficacy. 11.

Huang, J., Liu, F., Teng, Z., Chen, J., Zhao, J., Wang, X., Wu, Y., Xiao, J., Wang, Y., Wu, R., 2020a. Public behavior change, perceptions, depression, and anxiety in relation to the COVID-19 outbreak, Open Forum Infectious Diseases. Oxford University Press US, p. ofaa273.

Huang, L., Lei, W., Xu, F., Liu, H., Yu, L., 2020b. Emotional responses and coping strategies in nurses and nursing students during Covid-19 outbreak: A comparative study. PLoS ONE 15 (8), e0237303.

Huang, L., Wang, Y., Liu, J., Ye, P., Chen, X., Xu, H., Qu, H., Ning, G.J.M.s.m.i.m.j.o.e., research, c., 2020c. Factors influencing anxiety of health care workers in the radiology department with high exposure risk to COVID-19. 26, e926008-926001.

Huang, Y., Wang, Y., Zeng, L., Yang, J., Song, X., Rao, W., Li, H., Ning, Y., He, H., Li, T.J.F.i.p., 2020d. Prevalence and Correlation of Anxiety, Insomnia and Somatic Symptoms in a Chinese Population During the COVID-19 Epidemic. 11, 894. 
Jahanshahi, A.A., Dinani, M.M., Madavani, A.N., Li, J., Zhang, S.X., 2020. The distress of Iranian adults during the Covid-19 pandemic - More distressed than the Chinese and with different predictors. Brain Behav Immun 87, 124-125.

Jin, Z., Zhao, K.-b., Xia, Y.-y., Chen, R.-j., Yu, H., Tamutana, T.T., Yuan, Z., Shi, Y.-M., Adamseged, H.Y., Kogay, M.J.F.i.P.H., 2020. Relationship Between Psychological Responses and the Appraisal of Risk Communication During the Early Phase of the COVID-19 Pandemic: A Two-Wave Study of Community Residents in China. 8.

Juan, Y., Yuanyuan, C., Qiuxiang, Y., Cong, L., Xiaofeng, L., Yundong, Z., Jing, C., Peifeng, Q., Yan, L., Xiaojiao, X.J.C.P., 2020. Psychological distress surveillance and related impact analysis of hospital staff during the COVID-19 epidemic in Chongqing, China. 103, 152198.

Kessler, R.C., Green, J.G., Gruber, M.J., Sampson, N.A., Bromet, E., Cuitan, M., Furukawa, T.A., Gureje, O., Hinkov, H., Hu, C.Y.J.I.j.o.m.i.p.r., 2010. Screening for serious mental illness in the general population with the K6 screening scale: results from the WHO World Mental Health (WMH) survey initiative. 19 (S1), 4-22.

Kisely, S., Warren, N., McMahon, L., Dalais, C., Henry, I., Siskind, D., 2020. Occurrence, prevention, and management of the psychological effects of emerging virus outbreaks on healthcare workers: rapid review and meta-analysis. BMJ 369.

Krishnamoorthy, Y., Nagarajan, R., Saya, G.K., Menon, V., 2020. Prevalence of psychological morbidities among general population, healthcare workers and COVID19 patients amidst the COVID-19 pandemic: A systematic review and meta-analysis. Psychiatry research

293, 113382.

Kroenke, K., Spitzer, R.L., Williams, J.B., 2001. The PHQ $\square$ 9: validity of a brief depression severity measure. Journal of general internal medicine 16 (9), 606-613.

Kroenke, K., Spitzer, R.L., Williams, J.B., Löwe, B., 2009. An ultra-brief screening scale for anxiety and depression: the PHQ-4. Psychosomatics 50 (6), 613-621.

Lai, J., Ma, S., Wang, Y., Cai, Z., Hu, J., Wei, N., Wu, J., Du, H., Chen, T., Li, R., Tan, H., Kang, L., Yao, L., Huang, M., Wang, H., Wang, G., Liu, Z., Hu, S., 2020. Factors Associated With Mental Health Outcomes Among Health Care Workers Exposed to Coronavirus Disease 2019. JAMA Netw Open 3 (3), e203976.

Lam, S.C., Arora, T., Grey, I., Suen, L.K.P., Huang, E.Y.-z., Li, D., Lam, K.B.H.J.F.i.p., 2020. Perceived risk and protection from infection and depressive symptoms among healthcare workers in mainland China and Hong Kong during COVID-19. 11, 686.

Lee, Y., Rosenblat, J.D., Lee, J., Carmona, N.E., Subramaniapillai, M., Shekotikhina, M., Mansur, R.B., Brietzke, E., Lee, J.-H., Ho, R.C.J.J.o.a.d., 2018. Efficacy of antidepressants on measures of workplace functioning in major depressive disorder: A systematic review. 227, 406-415.

Lei, L., Huang, X., Zhang, S., Yang, J., Yang, L., Xu, M., 2020. Comparison of Prevalence and Associated Factors of Anxiety and Depression Among People Affected by versus People Unaffected by Quarantine During the COVID-19 Epidemic in Southwestern China. Med Sci Monit 26, e924609.

Leng, M., Wei, L., Shi, X., Cao, G., Wei, Y., Xu, H., Zhang, X., Zhang, W., Xing, S., Wei, H.J.N.i.C.C., 2020. Mental distress and influencing factors in nurses caring for patients with COVID $\square 19$.

Li, G., Miao, J, Wang, H, Xu, S, Sun, W, Fan, Y, et al., Psychological impact on women health workers involved in COVID-19 outbreak in Wuhan: a cross-sectional study.

Li, L., Sun, N., Fei, S., Yu, L., Chen, S., Yang, S., Li, H.J.J.J.o.N.S., 2020a. Current status of and factors influencing anxiety and depression in front $\square$ line medical staff supporting Wuhan in containing the novel coronavirus pneumonia epidemic. e12398. 
Li, Q., Chen, J., Xu, G., Zhao, J., Yu, X., Wang, S., Liu, L., Liu, F.J.F.i.P.H., 2020b. The Psychological Health Status of Healthcare Workers During the COVID-19 Outbreak: A Cross-Sectional Survey Study in Guangdong, China. 8, 572.

Li, Q., Miao, Y., Zeng, X., Tarimo, C.S., Wu, C., Wu, J.J.J.o.a.d., 2020c. Prevalence and factors for anxiety during the coronavirus disease 2019 (COVID-19) epidemic among the teachers in China. 277, 153-158.

Li, Q.J.Q.A.I.J.o.M., 2020a. Psychosocial and coping responses toward 2019 coronavirus diseases (COVID-19): a cross-sectional study within the Chinese general population. 113 (10), 731-738.

Li, R., Chen, Y., Lv, J., Liu, L., Zong, S., Li, H., Li, H.J.M., 2020d. Anxiety and related factors in frontline clinical nurses fighting COVID-19 in Wuhan. 99 (30).

Li, X., Li, S., Xiang, M., Fang, Y., Qian, K., Xu, J., Li, J., Zhang, Z., Wang, B.J.J.o.P.R., 2020e. The prevalence and risk factors of PTSD symptoms among medical assistance workers during the COVID-19 pandemic. 139, 110270.

Li, X., Yu, H., Bian, G., Hu, Z., Liu, X., Zhou, Q., . . Zhou, D., 2020b. Prevalence, risk factors, and clinical correlates of insomnia in volunteer and at home medical staff during the COVID-19. Brain, Behavior, and Immunity 87, 140-141.

Li, X., Zhou, Y., Xu, X.J.J.o.n.m., 2020f. Factors associated with the psychological well $\square$ being among front $\square$ line nurses exposed to COVID $\square 2019$ in China: A predictive study.

Li, Y., Qin, Q., Sun, Q., Sanford, L.D., Vgontzas, A.N., Tang, X., 2020g. Insomnia and psychological reactions during the COVID-19 outbreak in China. J Clin Sleep Med 16 (8), 1417-1418.

Liang, Y., Wu, K., Zhou, Y., Huang, X., Zhou, Y., Liu, Z.J.I.j.o.e.r., health, p., 2020. Mental health in frontline medical workers during the 2019 novel coronavirus disease epidemic in China: a comparison with the general population. 17 (18), 6550.

Lin, K., Yang, B.X., Luo, D., Liu, Q., Ma, S., Huang, R., Lu, W., Majeed, A., Lee, Y., Lui, L.M.J.A.J.o.P., 2020a. The mental health effects of COVID-19 on health care providers in China. 177 (7), 635-636.

Lin, L.-y., Wang, J., Ou-yang, X.-y., Miao, Q., Chen, R., Liang, F.-X., Zhang, Y.-p., Tang, Q., Wang, T.J.S.M., 2020b. The immediate impact of the 2019 novel coronavirus (COVID-19) outbreak on subjective sleep status.

Liu, C.-Y., Yang, Y.-z., Zhang, X.-M., Xu, X., Dou, Q.-L., Zhang, W.-W., \& Cheng, A. S. K., 2020. The prevalence and influencing factors in anxiety in medical workers fighting COVID-19 in China: a cross-sectional survey. Epidemiology and Infection 148.

Liu, D., Ren, Y., Yan, F., Li, Y., Xu, X., Yu, X., . . Tan, S., in press. Psychological Impact and Predisposing Factors of the Coronavirus Disease 2019 (COVID-19) Pandemic on General Public in China. Lancet Psychiatry.

Liu, M., Zhang, H., Huang, H.J.B.P.H., 2020a. Media exposure to COVID-19 information, risk perception, social and geographical proximity, and self-rated anxiety in China. 20 (1), 1-8.

Liu, N., Zhang, F., Wei, C., Jia, Y., Shang, Z., Sun, L., Wu, L., Sun, Z., Zhou, Y., Wang, Y., Liu, W., 2020b. Prevalence and predictors of PTSS during COVID-19 outbreak in China hardest-hit areas: Gender differences matter. Psychiatry Res 287, 112921.

Liu, X., Luo, W.-T., Li, Y., Li, C.-N., Hong, Z.-S., Chen, H.-L., Xiao, F., Xia, J.-Y.J.I.D.o.P., 2020c. Psychological status and behavior changes of the public during the COVID-19 epidemic in China. 9 (1), 1-11.

Liu, Y., Chen, H., Zhang, N., Wang, X., Fan, Q., Zhang, Y., Huang, L., Hu, B., Li, M.J.J.o.A.D., 2020d. Anxiety and depression symptoms of medical staff under COVID-19 epidemic in China. 278, 144-148. 
Liu, Y., Wang, L., Chen, L., Zhang, X., Bao, L., Shi, Y.J.F.i.p., 2020e. Mental health status of paediatric medical workers in China during the COVID-19 outbreak. 11.

Liu, Z., Han, B., Jiang, R.M., Huang, Y.Q., Ma, C., Wen, J., Zhang, T.T., Wang, Y., Chen, H.G., Ma, Y.C., 2020f. Mental health status of doctors and nurses during COVID-19 epidemic in China. Preprint with The Lancet, SSRN.

Lu, H., Nie, P., Qian, L.J.A.R.i.Q.o.L., 2020a. Do quarantine experiences and attitudes towards COVID-19 affect the distribution of mental health in China? A quantile regression analysis. 1-18.

Lu, P., Li, X., Lu, L., Zhang, Y.J.P.o., 2020b. The psychological states of people after Wuhan eased the lockdown. 15 (11), e0241173.

Lu, W., Wang, H., Lin, Y., Li, L., 2020c. Psychological status of medical workforce during the COVID-19 pandemic: A cross-sectional study. Psychiatry Research 288.

Luo, M., Guo, L., Yu, M., Wang, H., 2020. The psychological and mental impact of coronavirus disease 2019 (COVID-19) on medical staff and general public-A systematic review and meta-analysis. Psychiatry Research, 113190.

Matza, L.S., Morlock, R., Sexton, C., Malley, K., Feltner, D., 2010. Identifying HAM $\square$ A cutoffs for mild, moderate, and severe generalized anxiety disorder. International Journal of Methods in Psychiatric Research 19 (4), 223-232.

Mboua, P.C., Keubo, F.R.N., Fouaka, S.G.N.J.L.E.P., 2020. Anxiety and Depression Associated with the Management of COVID-19 Among Healthcare Personnel in Cameroon.

Mi, T., Yang, X., Sun, S., Li, X., Tam, C.C., Zhou, Y., Shen, Z.J.A., Behavior, 2020. Mental Health Problems of HIV Healthcare Providers During the COVID-19 Pandemic: The Interactive Effects of Stressors and Coping. 1-10.

Moccia, L., Janiri, D., Pepe, M., Dattoli, L., Molinaro, M., De Martin, V., Chieffo, D., Janiri, L., Fiorillo, A., Sani, G., Di Nicola, M., 2020. Affective temperament, attachment style, and the psychological impact of the COVID-19 outbreak: an early report on the Italian general population. Brain Behav Immun 87, 75-79.

Moghanibashi-Mansourieh, A., 2020. Assessing the anxiety level of Iranian general population during COVID-19 outbreak. Asian J Psychiatr 51, 102076.

Morin, C.M., Belleville, G., Bélanger, L., Ivers, H.J.S., 2011. The Insomnia Severity Index: psychometric indicators to detect insomnia cases and evaluate treatment response. 34 (5), 601-608.

Ni, M.Y., Yang, L., Leung, C.M.C., Li, N., Yao, X., Wang, Y., Leung, G.M., Cowling, B.J., Liao, Q., 2020a. Mental health, risk factors, and social media use during the COVID19 epidemic and cordon sanitaire among the community and health professionals in Wuhan, China: Cross-sectional survey. JMIR Ment Health 7 (5), e19009.

Ni, Z., Lebowitz, E.R., Zou, Z., Wang, H., Liu, H., Shrestha, R., Zhang, Q., Hu, J., Yang, S., Xu, L.J.J.o.U.H., 2020b. Response to the COVID-19 Outbreak in Urban Settings in China. 1-12.

Ning, X., Yu, F., Huang, Q., Li, X., Luo, Y., Huang, Q., Chen, C.J.B.p., 2020. The mental health of neurological doctors and nurses in Hunan Province, China during the initial stages of the COVID-19 outbreak. 20 (1), 1-9.

Ozamiz-Etxebarria, N., Dosil-Santamaria, M., Picaza-Gorrochategui, M., Idoiaga-Mondragon, N., 2020. Stress, anxiety, and depression levels in the initial stage of the COVID-19 outbreak in a population sample in the northern Spain. Cad Saude Publica 36 (4), e00054020.

Pan, X., Xiao, Y., Ren, D., Xu, Z.M., Zhang, Q., Yang, L.Y., Liu, F., Hao, Y.S., Zhao, F., Bai, Y.H.J.A.P.P., 2020a. Prevalence of mental health problems and associated risk 
factors among military healthcare workers in specialized COVID $\square 19$ hospitals in Wuhan, China: A cross $\square$ sectional survey. e12427.

Pan, Y., Fang, Y., Xin, M., Dong, W., Zhou, L., Hou, Q., Li, F., Sun, G., Zheng, Z., Yuan, J.J.J.o.m.I.r., 2020b. Self-reported compliance with personal preventive measures among Chinese factory workers at the beginning of work resumption following the COVID-19 outbreak: Cross-sectional survey study. 22 (9), e22457.

Pappa, S., Giannakoulis, V.G., Papoutsi, E., Katsaounou, P.J.B., Behavior,, Immunity, 2020. Author reply-Letter to the editor "The challenges of quantifying the psychological burden of COVID-19 on heathcare workers".

Pappa, S., Ntella, V., Giannakas, T., Giannakoulis, V. G., Papoutsi, E., \& Katsaounou, P., 2020. Prevalence of depression, anxiety, and insomnia among healthcare workers during the COVID-19 pandemic: A systematic review and meta-analysis. Brain, Behavior, and Immunity 88, 901-907.

Prins, A., Bovin, M.J., Smolenski, D.J., Marx, B.P., Kimerling, R., Jenkins-Guarnieri, M.A., Kaloupek, D.G., Schnurr, P.P., Kaiser, A.P., Leyva, Y.E.J.J.o.g.i.m., 2016. The primary care PTSD screen for DSM-5 (PC-PTSD-5): development and evaluation within a veteran primary care sample. 31 (10), 1206-1211.

Qi, J., Xu, J., Li, B.-Z., Huang, J.-S., Yang, Y., Zhang, Z.-T., . . Zhang, X., 2020. The evaluation of sleep disturbances for Chinese frontline medical workers under the outbreak of COVID-19. Sleep Medicine 72, 1-4.

Qian, M., Wu, Q., Wu, P., Hou, Z., Liang, Y., Cowling, B.J., Yu, H.J.B.o., 2020. Anxiety levels, precautionary behaviours and public perceptions during the early phase of the COVID-19 outbreak in China: a population-based cross-sectional survey. 10 (10), e040910.

Qian, M., Wu, Q., Wu, P., Hou, Z., Liang, Y., Cowling, B. J., \& Yu, H., 2020. Psychological responses, behavioral changes and public perceptions during the early phase of the COVID-19 outbreak in China: a population based cross-sectional survey.

Qiu, J., Shen, B., Zhao, M., Wang, Z., Xie, B., Xu, Y., 2020. A nationwide survey of psychological distress among Chinese people in the COVID-19 epidemic: implications and policy recommendations. Gen Psychiatr 33 (2), e100213.

Que, J., Shi, L., Deng, J., Liu, J., Zhang, L., Wu, S., Gong, Y., Huang, W., Yuan, K., Yan, W., Sun, Y., Ran, M., Bao, Y., Lu, L., 2020. Psychological impact of the COVID-19 pandemic on healthcare workers: a cross-sectional study in China. Gen Psychiatr 33 (3), e100259.

Ren, X., Huang, W., Pan, H., Huang, T., Wang, X., Ma, Y., 2020a. Mental health during the Covid-19 outbreak in China: a meta-analysis. Psychiatric Quarterly, 1-13.

Ren, Z., Zhou, Y., Liu, Y.J.B.p.h., 2020b. The psychological burden experienced by Chinese citizens during the COVID-19 outbreak: prevalence and determinants. 20 (1), 1-10.

Salari, N., Hosseinian-Far, A., Jalali, R., Vaisi-Raygani, A., Rasoulpoor, S., Mohammadi, M., Rasoulpoor, S., Khaledi-Paveh, B., 2020a. Prevalence of stress, anxiety, depression among the general population during the COVID-19 pandemic: a systematic review and meta-analysis. Globalization health 16 (1), 1-11.

Salari, N., Khazaie, H., Hosseinian-Far, A., Ghasemi, H., Mohammadi, M., Shohaimi, S., Daneshkhah, A., Khaledi-Paveh, B., Hosseinian-Far, M., 2020b. The prevalence of sleep disturbances among physicians and nurses facing the COVID-19 patients: a systematic review and meta-analysis. Globalization health

$16(1), 1-14$.

Schlenger, W.E., Caddell, J.M., Ebert, L., Jordan, B.K., Rourke, K.M., Wilson, D., Thalji, L., Dennis, J.M., Fairbank, J.A., Kulka, R.A.J.J., 2002. Psychological reactions to 
terrorist attacks: findings from the National Study of Americans' Reactions to September 11. 288 (5), 581-588.

Shi, L., Lu, Z.-A., Que, J.-Y., Huang, X.-L., Liu, L., Ran, M.-S., Gong, Y.-M., Yuan, K., Yan, W., Sun, Y.-K.J.J.n.o., 2020. Prevalence of and risk factors associated with mental health symptoms among the general population in China during the coronavirus disease 2019 pandemic. 3 (7), e2014053-e2014053.

Si, M., Su, X., Jiang, Y., Wang, W., Gu, X.-f., Ma, L., Li, J., Zhang, S., Ren, Z.-F., Liu, Y.L.J.A.a.S., 2020. The psychological impact of COVID-19 on medical care workers in China.

Soldatos, C.R., Dikeos, D.G., Paparrigopoulos, T.J.J.J.o.p.r., 2000. Athens Insomnia Scale: validation of an instrument based on ICD-10 criteria. 48 (6), 555-560.

Song, L., Wang, Y., Li, Z., Yang, Y., Li, H.J.I.j.o.e.r., health, p., 2020. Mental health and work attitudes among people resuming work during the Covid-19 pandemic: A crosssectional study in China. 17 (14), 5059.

Song, X., Fu, W., Liu, X., Luo, Z., Wang, R., Zhou, N., . . Lv, C. , 2020. Mental health status of medical staff in emergency departments during the Coronavirus disease 2019 epidemic in China. Brain Behav Immun 88, 60-65.

Spitzer, R.L., Kroenke, K., Williams, J.B., Löwe, B., 2006. A brief measure for assessing generalized anxiety disorder: the GAD-7. Archives of internal medicine 166 (10), 1092-1097.

Su, J., Chen, X., Yang, N., Sun, M., Zhou, L.J.B.o., 2020. Proximity to people with COVID19 and anxiety among community residents during the epidemic in Guangzhou, China. 6 (4).

Sun, H., Wang, S., Wang, W., Han, G., Liu, Z., Wu, Q., Pang, X.J.J.o.c.n., 2020a. Correlation between emotional intelligence and negative emotions of front $\square$ line nurses during the COVID $\square 19$ epidemic: a cross $\square$ sectional study.

Sun, L., Sun, Z., Wu, L., Zhu, Z., Zhang, F., Shang, Z., . . Liu, W., 2020. Prevalence and Risk Factors of Acute Posttraumatic Stress Symptoms during the COVID-19 Outbreak in Wuhan, China.

Sun, Q., Lu, N.J.I.j.o.e.r., health, p., 2020b. Social Capital and Mental Health among Older Adults Living in Urban China in the Context of COVID-19 Pandemic. 17 (21), 7947.

Sun, Y., Song, H., Liu, H., Mao, F., Sun, X., Cao, F.J.I.J.o.S.P., 2020c. Occupational stress, mental health, and self-efficacy among community mental health workers: A crosssectional study during COVID-19 pandemic. 0020764020972131.

Tan, W., Hao, F., McIntyre, R.S., Jiang, L., Jiang, X., Zhang, L., Zhao, X., Zou, Y., Hu, Y., Luo, X., Zhang, Z., Lai, A., Ho, R., Tran, B., Ho, C., Tam, W., 2020. Is returning to work during the COVID-19 pandemic stressful? A study on immediate mental health status and psychoneuroimmunity prevention measures of Chinese workforce. Brain Behav Immun 87, 84-92.

Tang, P.M., Zhang, S.X., Li, C.H., Wei, F., 2020. Geographical identification of the vulnerable groups during COVID-19 crisis: the typhoon eye effect and its boundary conditions. MedRxiv.

Temsah, M.-H., Al-Sohime, F., Alamro, N., Al-Eyadhy, A., Al-Hasan, K., Jamal, A., . . Somily, A. M., 2020. The psychological impact of COVID-19 pandemic on health care workers in a MERS-CoV endemic country. Journal of Infection and Public Health 13 (6), 877-882.

Teng, Z., Wei, Z., Qiu, Y., Tan, Y., Chen, J., Tang, H., Wu, H., Wu, R., Huang, J.J.J.o.a.d., 2020. Psychological status and fatigue of frontline staff two months after the COVID19 pandemic outbreak in China: A cross-sectional study. 
Teshome, A., Glagn, M., Shegaze, M., Tekabe, B., Getie, A., Assefa, G., Getahun, D., Kanko, T., Getachew, T., Yenesew, N.J.P.R., Management, B., 2020. Generalized Anxiety Disorder and Its Associated Factors Among Health Care Workers Fighting COVID19 in Southern Ethiopia. 13, 907.

Thoresen, S., Tambs, K., Hussain, A., Heir, T., Johansen, V.A., Bisson, J.I.J.S.p., epidemiology, p., 2010. Brief measure of posttraumatic stress reactions: Impact of Event Scale-6. 45 (3), 405-412.

Tsai, P.-S., Wang, S.-Y., Wang, M.-Y., Su, C.-T., Yang, T.-T., Huang, C.-J., Fang, S.C.J.Q.o.L.R., 2005. Psychometric evaluation of the Chinese version of the Pittsburgh Sleep Quality Index (CPSQI) in primary insomnia and control subjects. 14 (8), 19431952.

Tu, Z.H., He, J.W., Zhou, N., 2020. Sleep quality and mood symptoms in conscripted frontline nurse in Wuhan, China during COVID-19 outbreak: A cross-sectional study. Medicine (Baltimore) 99 (26), e20769.

Usher, K., Jackson, D., Durkin, J., Gyamfi, N., Bhullar, N., 2020. Pandemic $\square$ related behaviours and psychological outcomes; A rapid literature review to explain COVID $\square 19$ behaviours. International Journal of Mental Health Nursing 29 (6), 10181034.

Wang, H., Huang, D., Huang, H., Zhang, J., Guo, L., Liu, Y., Ma, H., Geng, Q., 2020a. The psychological impact of COVID-19 pandemic on medical staff in Guangdong, China: a cross-sectional study. Psychol Med, 1-9.

Wang, J., Gong, Y., Chen, Z., Wu, J., Feng, J., Yan, S., Lv, C., Lu, Z., Mu, K., Yin, X.J.S.m., 2020b. Sleep disturbances among Chinese residents during the Coronavirus Disease 2019 outbreak and associated factors. 74, 199-203.

Wang, J., Guo, W.-j., Zhang, L., Deng, W., Wang, H.-y., Yu, J.-y., Luo, S.-x., Huang, M.-j., Dong, Z.-q., Li, D.-J.J.C.p., 2017. The development and validation of Huaxi emotional-distress index (HEI): a Chinese questionnaire for screening depression and anxiety in non-psychiatric clinical settings. 76, 87-97.

Wang, L.-Q., Zhang, M., Liu, G.-M., Nan, S.-Y., Li, T., Xu, L., Xue, Y., Zhang, M., Wang, L., Qu, Y.-D.J.J.o.P.R., 2020c. Psychological impact of coronavirus disease (2019)(COVID-19) epidemic on medical staff in different posts in China: A multicenter study. 129, 198-205.

Wang, S., Xie, L., Xu, Y., Yu, S., Yao, B., Xiang, D., 2020d. Sleep disturbances among medical workers during the outbreak of COVID-2019. Occup Med (Lond) 70 (5), 364-369.

Wang, S., Zhang, Y., Ding, W., Meng, Y., Hu, H., Liu, Z., Zeng, X., Wang, M.J.E.P., 2020e. Psychological distress and sleep problems when people are under interpersonal isolation during an epidemic: a nationwide multicenter cross-sectional study. 63 (1).

Wang, W., Song, W., Xia, Z., He, Y., Tang, L., Hou, J., Lei, S.J.F.i.p., 2020f. Sleep disturbance and psychological profiles of medical staff and non-medical staff during the early outbreak of COVID-19 in Hubei Province, China. 11, 733.

Wang, Y.-X., Guo, H.-T., Du, X.-W., Song, W., Lu, C., Hao, W.-N.J.M., 2020g. Factors associated with post-traumatic stress disorder of nurses exposed to corona virus disease 2019 in China. 99 (26).

Wang, Y., Di, Y., Ye, J., Wei, W., 2020h. Study on the public psychological states and its related factors during the outbreak of coronavirus disease 2019 (COVID-19) in some regions of China. Psychol Health Med, 1-10.

Wang, Y., Hu, Z., Feng, Y., Wilson, A., Chen, R.J.M.p., 2020i. Changes in network centrality of psychopathology symptoms between the COVID-19 outbreak and after peak. 25 (12), 3140-3149. 
Wang, Y., Ma, S., Yang, C., Cai, Z., Hu, S., Zhang, B., Tang, S., Bai, H., Guo, X., Wu, J.J.T.p., 2020j. Acute psychological effects of Coronavirus Disease 2019 outbreak among healthcare workers in China: a cross-sectional study. 10 (1), 1-10.

Wang, Z., Yuan, C.-M., Huang, J., Li, Z.-Z., Chen, J., Zhang, H.-Y., Fang, Y.-R., Xiao, Z.P.J.C.M.H.J., 2011. Reliability and validity of the Chinese version of Beck Depression Inventory-II among depression patients.

Wilberforce, N., Wilberforce, K., Aubrey-Bassler, F.K.J.F.p., 2010. Post-traumatic stress disorder in physicians from an underserviced area. 27 (3), 339-343.

World Health Organization, 2020. World Health Organization coronavirus disease (COVID19) dashboard.

Wu, K.K., Chan, K.J.S.p., epidemiology, p., 2003. The development of the Chinese version of Impact of Event Scale-Revised (CIES-R). 38 (2), 94-98.

Wu, L., Guo, X., Shang, Z., Sun, Z., Jia, Y., Sun, L., Liu, W., 2020a. China experience from COVID-19: Mental health in mandatory quarantine zones urgently requires intervention.

Wu, M., Han, H., Lin, T., Chen, M., Wu, J., Du, X., Su, G., Wu, D., Chen, F., Zhang, Q.J.B., behavior, 2020b. Prevalence and risk factors of mental distress in China during the outbreak of COVID $\square$ 19: A national cross $\square$ sectional survey. 10 (11), e01818.

Wu, S., Li, Z., Li, Z., Xiang, W., Yuan, Y., Liu, Y., Xiong, Z.J.C.p., 2020c. The mental state and risk factors of Chinese medical staff and medical students in early stages of the COVID-19 epidemic. 102, 152202.

Xiao, X., Zhu, X., Fu, S., Hu, Y., Li, X., Xiao, J.J.J.o.A.D., 2020. Psychological impact of healthcare workers in China during COVID-19 pneumonia epidemic: a multi-center cross-sectional survey investigation.

Xiaoming, X., Ming, A., Su, H., Wo, W., Jianmei, C., Qi, Z., Hua, H., Xuemei, L., Lixia, W., Jun, C.J.J.o.a.d., 2020. The psychological status of 8817 hospital workers during COVID-19 Epidemic: A cross-sectional study in Chongqing. 276, 555-561.

Xing, L.-q., Xu, M.-l., Sun, J., Wang, Q.-X., Ge, D.-d., Jiang, M.-m., Du, W., Li, Q.J.I.J.o.S.P., 2020. Anxiety and depression in frontline health care workers during the outbreak of Covid-19. 0020764020968119.

Xiong, H., Yi, S., Lin, Y.J.I.T.J.o.H.C.O., Provision,, Financing, 2020. The psychological status and self-efficacy of nurses during COVID-19 outbreak: a cross-sectional survey. 57, 0046958020957114.

Xu, H., Li, Y., Zeng, M., Zhao, X., Li, T.J.F.i.P., 2020. Psychological Behavior of Frontline Medical Staff in the Use of Preventive Medication for COVID-19: A Cross-Sectional Study. 11, 2104.

Yáñez, J.A., Jahanshahi, A. A., Alvarez-Risco, A., Li, J., \& Zhang, S. X. , 2020. Anxiety, Distress, and Turnover Intention of Healthcare Workers in Peru by Their Distance to the Epicenter during the COVID-19 Crisis. The American Journal of Tropical Medicine and Hygiene 103 (4), 1614 - 1620.

Yang, X., Zhang, Y., Li, S., Chen, X.J.S.p., epidemiology, p., 2020a. Risk factors for anxiety of otolaryngology healthcare workers in Hubei province fighting coronavirus disease 2019 (COVID-19). 1-7.

Yang, Y., Zhu, J.-f., Yang, S.-y., Lin, H.-j., Chen, Y., Zhao, Q., Fu, C.-w.J.S.m., 2020 b. Prevalence and associated factors of poor sleep quality among Chinese returning workers during the COVID-19 pandemic. 73, 47-52.

Yin, Q., Sun, Z., Liu, T., Ni, X., Deng, X., Jia, Y., Shang, Z., Zhou, Y., Liu, W.J.C.P., Psychotherapy, 2020. Posttraumatic Stress Symptoms of Health Care Workers during the Corona Virus Disease 2019 (COVID $\square$ 19). 
Yin, X., Wang, J., Feng, J., Chen, Z., Jiang, N., Wu, J., Yan, S., Li, H., The Impact of the Corona Virus Disease 2019 Outbreak on Chinese Residents' Mental Health.

Ying, Y., Ruan, L., Kong, F., Zhu, B., Ji, Y., Lou, Z.J.B.p., 2020. Mental health status among family members of health care workers in Ningbo, China, during the coronavirus disease 2019 (COVID-19) outbreak: a cross-sectional study. 20 (1), 1-10.

Yu, B.Y.-M., Yeung, W.-F., Lam, J.C.-S., Yuen, S.C.-S., Lam, S.C., Chung, V.C.-H., Chung, K.-F., Lee, P.H., Ho, F.Y.-Y., Ho, J.Y.-S.J.S.m., 2020a. Prevalence of sleep disturbances during covid-19 outbreak in an urban Chinese population: a crosssectional study. 74, 18-24.

Yu, H., Li, M., Li, Z., Xiang, W., Yuan, Y., Liu, Y., Li, Z., Xiong, Z., 2020b. Coping style, social support and psychological distress in the general Chinese population in the early stages of the COVID-2019 epidemic. SSRN.

Zhan, Y.-x., Zhao, S.-y., Yuan, J., Liu, H., Liu, Y.-f., Gui, L.-1., Zheng, H., Zhou, Y.-m., Qiu, L.-h., Chen, J.-h.J.C.m.s., 2020a. Prevalence and Influencing Factors on Fatigue of First-line Nurses Combating with COVID-19 in China: A Descriptive Cross-Sectional Study. 40 (4), 625-635.

Zhan, Y., Liu, Y., Liu, H., Li, M., Shen, Y., Gui, L., Zhang, J., Luo, Z., Tao, X., Yu, J.J.J.o.n.m., 2020b. Factors associated with insomnia among Chinese front $\square$ line nurses fighting against COVID $\square 19$ in Wuhan: A cross $\square$ sectional survey. 28 (7), $1525-1535$.

Zhang, C., Peng, D., Lv, L., Zhuo, K., Yu, K., Shen, T., Xu, Y., Wang, Z.J.N.d., treatment, 2020a. Individual Perceived Stress Mediates Psychological Distress in Medical Workers During COVID-19 Epidemic Outbreak in Wuhan. 16, 2529.

Zhang, C., Yang, L., Liu, S., Ma, S., Wang, Y., Cai, Z., Du, H., Li, R., Kang, L., Su, M., Zhang, J., Liu, Z., Zhang, B., 2020b. Survey of Insomnia and Related Social Psychological Factors Among Medical Staff Involved in the 2019 Novel Coronavirus Disease Outbreak. Front Psychiatry 11, 306.

Zhang, H., Shi, Y., Jing, P., Zhan, P., Fang, Y., Wang, F.J.P.r., 2020c. Posttraumatic stress disorder symptoms in healthcare workers after the peak of the COVID-19 outbreak: A survey of a large tertiary care hospital in Wuhan. 294, 113541.

Zhang, J., Lu, H., Zeng, H., Zhang, S., Du, Q., Jiang, T., \& Dua, B., 2020. The differential psychological distress of populations affected by the COVID-19 pandemic. Brain, Behavior, and Immunity 87, 49-50.

Zhang, L., Ma, M., Li, D., Xin, Z., 2020d. The psychological typhoon eye effect during the COVID-19 outbreak in China: the role of coping efficacy and perceived threat. Globalization health 16 (1), 1-10.

Zhang, S.X., Huang, H., Wei, F.J.P.r., 2020e. Geographical distance to the epicenter of Covid-19 predicts the burnout of the working population: Ripple effect or typhoon eye effect? Psychiatry Research 288, 112998.

Zhang, S.X., Liu, J., Afshar Jahanshahi, A., Nawaser, K., Yousefi, A., Li, J., Sun, S., $2020 \mathrm{f}$. At the height of the storm: Healthcare staff's health conditions and job satisfaction and their associated predictors during the epidemic peak of COVID-19. Brain Behav Immun 87, 144-146.

Zhang, S.X., Wang, Y., Jahanshahi, A.A., Li, J., Schmitt, V.G.H., Early evidence and predictors of mental distress of adults one month in the COVID-19 epidemic in Brazil. Journal of Psychosomatic Research, 110366.

Zhang, S.X., Wang, Y., Jahanshahi, A.A., Schmitt, V.G.H., 2020g. First study on mental distress in Brazil during the COVID-19 crisis. MedRxiv. 
Zhang, S.X., Wang, Y., Rauch, A., Wei, F., 2020h. Unprecedented disruption of lives and work: Health, distress and life satisfaction of working adults in China one month into the COVID-19 outbreak. Psychiatry Research 288, 112958.

Zhang, W., Yang, X., Zhao, J., Yang, F., Jia, Y., Cui, C., Yang, X.J.J.o.m.I.r., 2020i. Depression and Psychological-Behavioral Responses Among the General Public in China During the Early Stages of the COVID-19 Pandemic: Survey Study. 22 (9), e22227.

Zhang, W.R., Wang, K., Yin, L., Zhao, W.F., Xue, Q., Peng, M., Min, B.Q., Tian, Q., Leng, H.X., Du, J.L., Chang, H., Yang, Y., Li, W., Shangguan, F.F., Yan, T.Y., Dong, H.Q., Han, Y., Wang, Y.P., Cosci, F., Wang, H.X., 2020j. Mental Health and Psychosocial Problems of Medical Health Workers during the COVID-19 Epidemic in China. Psychother Psychosom 89 (4), 242-250.

Zhang, X.-R., Huang, Q.-M., Wang, X.-M., Cheng, X., Li, Z.-H., Wang, Z.-H., Zhong, W.-F., Liu, D., Shen, D., Chen, P.-L.J.J.o.a.d., 2020k. Prevalence of anxiety and depression symptoms, and association with epidemic-related factors during the epidemic period of COVID-19 among 123,768 workers in China: A large cross-sectional study. 277, 495-502.

Zhang, Y., Cao, X., Wang, P., Wang, G., Lei, G., Shou, Z., Xie, S., Huang, F., Luo, N., Luo, M., 20201. Emotional "inflection point" in public health emergencies with the 2019 new coronavirus pneumonia (NCP) in China. Journal of affective disorders 276, 797 803.

Zhang, Y., Ma, Z.F., 2020. Impact of the COVID-19 Pandemic on Mental Health and Quality of Life among Local Residents in Liaoning Province, China: A Cross-Sectional Study. Int J Environ Res Public Health 17 (7).

Zhang, Y., Wang, S., Ding, W., Meng, Y., Hu, H., Liu, Z., Zeng, X., Guan, Y., Wang, M.J.J.o.P.R., 2020m. Status and influential factors of anxiety depression and insomnia symptoms in the work resumption period of COVID-19 epidemic: A multicenter cross-sectional study. 138, 110253.

Zhao, K., Zhang, G., Feng, R., Wang, W., Xu, D., Liu, Y., Chen, L.J.P.R., 2020a. Anxiety, depression and insomnia: A cross-sectional study of frontline staff fighting against COVID-19 in Wenzhou, China. 292, 113304.

Zhao, S.Z., Wong, J.Y.H., Luk, T.T., Wai, A.K.C., Lam, T.H., Wang, M.P.J.I.J.o.I.D., 2020b. Mental health crisis under COVID-19 pandemic in Hong Kong, China. 100, 431-433.

Zhao, X., Lan, M., Li, H., Yang, J.J.S.M., 2020c. Perceived Stress and Sleep Quality Among the Non-diseased General Public in China During the 2019 Coronavirus Disease: A Moderated Mediation Model.

Zhou, T., Nguyen, T.-v.T., Zhong, J., Liu, J.J.R.S.o.s., 2020a. A COVID-19 descriptive study of life after lockdown in Wuhan, China. 7 (9), 200705.

Zhou, Y., Wang, W., Sun, Y., Qian, W., Liu, Z., Wang, R., Qi, L., Yang, J., Song, X., Zhou, X.J.J.o.a.d., 2020b. The prevalence and risk factors of psychological disturbances of frontline medical staff in china under the COVID-19 epidemic: Workload should be concerned. 277, 510-514.

Zhou, Y., Yang, Y., Shi, T., Song, Y., Zhou, Y., Zhang, Z., Guo, Y., Li, X., Liu, Y., Xu, G., Cheung, T., Xiang, Y.T., Tang, Y., 2020c. Prevalence and Demographic Correlates of Poor Sleep Quality Among Frontline Health Professionals in Liaoning Province, China During the COVID-19 Outbreak. Front Psychiatry 11, 520.

Zhu, J., Sun, L., Zhang, L., Wang, H., Fan, A., Yang, B., Li, W., Xiao, S., 2020a. Prevalence and Influencing Factors of Anxiety and Depression Symptoms in the First-Line Medical Staff Fighting Against COVID-19 in Gansu. Front Psychiatry 11, 386. 
medRxiv preprint doi: https://doi.org/10.1101/2021.02.01.21250929; this version posted April 30, 2021. The copyright holder for this preprint

(which was not certified by peer review) is the author/funder, who has granted medRxiv a license to display the preprint in perpetuity.

It is made available under a CC-BY-ND 4.0 International license .

Zhu, S., Wu, Y., Zhu, C.Y., Hong, W.C., Yu, Z.X., Chen, Z.K., Chen, Z.L., Jiang, D.G., Wang, Y.G., 2020b. The immediate mental health impacts of the COVID-19 pandemic among people with or without quarantine managements. Brain Behav Immun 87, 56-58.

Zhu, W., Wei, Y., Meng, X., Li, J.J.B.h.s.r., 2020c. The mediation effects of coping style on the relationship between social support and anxiety in Chinese medical staff during COVID-19. 20 (1), 1-7.

Zhu, Z., Xu, S., Wang, H., Liu, Z., Wu, J., Li, G., . . Wang, W., 2020. COVID-19 in Wuhan: Immediate Psychological Impact on 5062 Health Workers. MedRxiv.

Zhuo, K., Gao, C., Wang, X., Zhang, C., Wang, Z.J.G.P., 2020. Stress and sleep: a survey based on wearable sleep trackers among medical and nursing staff in Wuhan during the COVID-19 pandemic. 33 (3).

Zigmond, A.S., Snaith, R.P., 1983. The hospital anxiety and depression scale. Acta psychiatrica scandinavica 67 (6), 361-370.

Zimmerman, M., Martinez, J.H., Young, D., Chelminski, I., Dalrymple, K., 2013. Severity classification on the Hamilton depression rating scale. Journal of affective disorders 150 (2), 384-388.

Zung, W.W., 1965. A self-rating depression scale. Archives of general psychiatry 12 (1), 63 70.

Zung, W.W., 1971. A rating instrument for anxiety disorders. Psychosomatics: Journal of Consultation and Liaison Psychiatry.

王春芳, 蔡则环, 徐清, 1986. 抑郁自评量表一SDS 对 1,340 例正常人评定分析. 中国神经

精神疾病杂志 12 (5), 267-268. 
Table 1. Characteristics of the studies on mental health in China in a year of COVID-19 epidemic

\begin{tabular}{|c|c|c|c|}
\hline Characteristics & $\begin{array}{l}\text { Total number of } \\
\text { studies/samples }\end{array}$ & Percent & Level of analysis \\
\hline Overall & 131 & 100 & Article \\
\hline Population & & & Sample \\
\hline Frontline HCWs & 47 & 27.5 & \\
\hline General HCWs & 46 & 26.9 & \\
\hline General population & 78 & 45.6 & \\
\hline Outcome & & & Prevalence \\
\hline Anxiety & 127 & 35.5 & \\
\hline Depression & 128 & 35.8 & \\
\hline Distress & 9 & 2.5 & \\
\hline General psychological symptoms & 7 & 2.0 & \\
\hline Insomnia & 57 & 15.9 & \\
\hline PTSD & 30 & 8.4 & \\
\hline Severity & & & Prevalence \\
\hline Above mild & 85 & 23.7 & \\
\hline Above moderate & 166 & 46.4 & \\
\hline Above severe & 107 & 29.9 & \\
\hline Sampling location & & & Article \\
\hline Wuhan & 38 & 22.2 & \\
\hline Non-Wuhan & 123 & 77.8 & \\
\hline Sampling date & & & Article \\
\hline January 2020 & 9 & 6.9 & \\
\hline February 2020 & 85 & 64.9 & \\
\hline March 2020 & 23 & 17.6 & \\
\hline April 2020 & 8 & 6.1 & \\
\hline May 2020 & 2 & 1.5 & \\
\hline June 2020 & 2 & 1.5 & \\
\hline July 2020 & 2 & 1.5 & \\
\hline Design & & & Article \\
\hline Cross-sectional & 126 & 96.2 & \\
\hline Cohort & 5 & 3.8 & \\
\hline Publication status & & & Article \\
\hline Preprint & 10 & 7.6 & \\
\hline Accepted & 1 & 0.8 & \\
\hline Published & 120 & 91.6 & \\
\hline Quality & & & Article \\
\hline Good & 100 & 73.3 & \\
\hline \multirow[t]{2}{*}{ Medium } & 31 & 23.7 & \\
\hline & Median & Range & \\
\hline Number of participants & 709 & $30-123,768$ & Article \\
\hline Female portion & $69 \%$ & $12 \%-100 \%$ & Article \\
\hline Response rate & $85 \%$ & $14 \%-100 \%$ & Article \\
\hline
\end{tabular}


Table 2. The pooled prevalence rates of mental health disorders by subgroups of population, outcome, and severity

\begin{tabular}{|c|c|c|c|c|c|c|c|c|}
\hline $\begin{array}{l}\text { First-level } \\
\text { subgroup }\end{array}$ & $\begin{array}{r}\text { Second-level } \\
\text { subgroup }\end{array}$ & $\begin{array}{l}\text { Number of } \\
\text { samples }(\mathrm{K})\end{array}$ & Percent & $\begin{array}{c}\text { Sample } \\
\text { size }(\mathrm{N})\end{array}$ & $\begin{array}{r}\text { Prevalence } \\
(\%)\end{array}$ & $95 \% \mathrm{CI}$ & $\mathrm{I} 2(\%)$ & $\begin{array}{r}\mathrm{P} \\
\text { value }\end{array}$ \\
\hline Overall & & $171^{*}$ & & 630,244 & 14 & $13-15$ & 99.9 & 0.00 \\
\hline \multirow{3}{*}{ Population } & Frontline HCWs & 47 & 27.5 & 65,477 & 17 & $14-20$ & 99.6 & 0.00 \\
\hline & General HCWs & 46 & 26.9 & 71,341 & 14 & $11-17$ & 99.7 & 0.00 \\
\hline & $\begin{array}{r}\text { General } \\
\text { population }\end{array}$ & 78 & 45.6 & 493,426 & 12 & $10-14$ & 99.9 & 0.00 \\
\hline \multirow{6}{*}{ Outcome\# } & Anxiety & 127 & 60.7 & 517,417 & 11 & $9-13$ & 99.8 & 0.00 \\
\hline & Depression & 128 & 61.1 & 444,008 & 13 & $11-16$ & 99.8 & 0.00 \\
\hline & Distress & 9 & 4.3 & 68,820 & 20 & $8-36$ & 99.9 & 0.00 \\
\hline & GPS & 7 & 3.3 & 35,966 & 13 & $3-27$ & 99.9 & 0.00 \\
\hline & Insomnia & 57 & 27.2 & 141,337 & 19 & $15-24$ & 99.7 & 0.00 \\
\hline & PTSD & 30 & 14.3 & 31,850 & 20 & $12-29$ & 99.7 & 0.00 \\
\hline \multirow{3}{*}{ Severity\# } & Above mild & 85 & 40.6 & 100,287 & 27 & $24-30$ & 99.3 & 0.00 \\
\hline & Above moderate & 166 & 79.3 & 515,676 & 18 & $16-20$ & 99.6 & 0.00 \\
\hline & Above severe & 107 & 51.1 & 622,526 & 3 & $2-3$ & 99.4 & 0.00 \\
\hline
\end{tabular}

Note: $\mathrm{CI}=$ Confidence Interval; $\mathrm{I}^{2}$ statistic indicates the heterogeneity. GPS = general psychological symptoms.

* The total independent samples are larger than the number of studies because some studies included multiple samples.

\# The total sample sizes are larger than the total sample of the 171 independent samples because one sample can assess multiple mental health outcomes. 
Table 3. The results of meta-regression of mental health disorders during COVID-19

\begin{tabular}{|c|c|c|c|}
\hline Variables & Coefficient (CI, 95\%) & Std. Err. & P-value \\
\hline \multicolumn{4}{|l|}{ Outcome } \\
\hline \multicolumn{4}{|l|}{ Anxiety (reference) } \\
\hline Depression & $0.03(-0.06$ to 0.11$)$ & 0.04 & 0.55 \\
\hline Distress & $0.24 *(0.01$ to 0.47$)$ & 0.12 & 0.04 \\
\hline General psychological symptoms & $-0.01(-0.27$ to 0.26$)$ & 0.14 & 0.97 \\
\hline Insomnia & $0.12 *(0.01$ to 0.23$)$ & 0.06 & 0.04 \\
\hline PTSD & $0.10(-0.05$ to 0.24$)$ & 0.07 & 0.20 \\
\hline \multicolumn{4}{|l|}{ Severity } \\
\hline Above mild & $0.20 * * *(0.11$ to 0.30$)$ & 0.05 & 0.00 \\
\hline \multicolumn{4}{|l|}{ Above moderate (reference) } \\
\hline Above severe & $-0.49 * * *(-0.58$ to 0.40$)$ & 0.05 & 0.00 \\
\hline \multicolumn{4}{|l|}{ Population } \\
\hline Frontline $\mathrm{HCWs}$ & $0.14 * * *(0.05$ to 0.23$)$ & 0.05 & 0.00 \\
\hline \multicolumn{4}{|l|}{ General HCWs (reference) } \\
\hline General population & $0.03(-0.07$ to 0.13$)$ & 0.05 & 0.51 \\
\hline \multicolumn{4}{|l|}{ Publication Status } \\
\hline \multicolumn{4}{|l|}{ Preprint (reference) } \\
\hline Accepted & $-0.34(-0.84$ to 0.17$)$ & 0.26 & 0.19 \\
\hline Published & $-0.02(-0.17$ to 0.13$)$ & 0.08 & 0.80 \\
\hline Female proportion & $0.09(-0.19$ to 0.37$)$ & 0.14 & 0.54 \\
\hline Date of data collection & $0.00(0.00$ to 0.00$)$ & 0.00 & 0.64 \\
\hline Wuhan vs. Non-Wuhan sample & $-0.10 *(-0.20$ to 0.00$)$ & 0.05 & 0.04 \\
\hline Sample size & $0.00(0.00$ to 0.00$)$ & 0.00 & 0.16 \\
\hline Quality & $0.08 *(0.01$ to 0.15$)$ & 0.04 & 0.03 \\
\hline Constant & 5.99 & 12.36 & 0.63 \\
\hline $\mathrm{R}^{2}$ & 0.41 & & \\
\hline Wald $X^{2}(16)$ & $252.05^{* * *}$ & & 0.00 \\
\hline
\end{tabular}


Table 4. The predicted prevalence rates of mental health disorders by populations, outcomes, and severity by the meta-analytical regression model

\begin{tabular}{lllll}
\hline & & \multicolumn{1}{c}{ Prevalence rate (95\% CI) } & \\
\hline $\begin{array}{l}\text { Mental health disorders } \\
\text { above certain severity }\end{array}$ & Frontline HCWs & General HCWs & General population & Overall \\
\hline Sample & $\mathrm{K}=47, \mathrm{~N}=65,477$ & $\mathrm{~K}=46, \mathrm{~N}=71,341$ & $\mathrm{~K}=78, \mathrm{~N}=493,426$ & $\mathrm{~K}=171, \mathrm{~N}=630,244$ \\
\hline Mild anxiety & $28 \%(23 \%-33 \%)$ & $22 \%(17 \%-26 \%)$ & $23 \%(19 \%-28 \%)$ & $24 \%(20 \%-28 \%)$ \\
Moderate anxiety & $19 \%(15 \%-23 \%)$ & $14 \%(11 \%-17 \%)$ & $15 \%(12 \%-19 \%)$ & $16 \%(13 \%-19 \%)$ \\
Severe anxiety & $4 \%(2 \%-6 \%)$ & $2 \%(1 \%-3 \%)$ & $2 \%(1 \%-4 \%)$ & $3 \%(2 \%-4 \%)$ \\
Mild depression & $29 \%(24 \%-34 \%)$ & $23 \%(19 \%-27 \%)$ & $24 \%(20 \%-29 \%)$ & $25 \%(21 \%-29 \%)$ \\
Moderate depression & $20 \%(17 \%-24 \%)$ & $15 \%(12 \%-18 \%)$ & $16 \%(13 \%-20 \%)$ & $17 \%(14 \%-20 \%)$ \\
Severe depression & $5 \%(3 \%-7 \%)$ & $2 \%(1 \%-4 \%)$ & $3 \%(1 \%-5 \%)$ & $3 \%(2 \%-5 \%)$ \\
Mild distress & $39 \%(27 \%-51 \%)$ & $32 \%(22 \%-44 \%)$ & $34 \%(23 \%-46 \%)$ & $35 \%(24 \%-47 \%)$ \\
Moderate distress & $29 \%(19 \%-41 \%)$ & $23 \%(14 \%-34 \%)$ & $25 \%(15 \%-35 \%)$ & $26 \%(16 \%-36 \%)$ \\
Severe distress & $10 \%(4 \%-19 \%)$ & $6 \%(2 \%-13 \%)$ & $7 \%(2 \%-15 \%)$ & $8 \%(3 \%-15 \%)$ \\
Mild GPS & $28 \%(16 \%-41 \%)$ & $21 \%(11 \%-34 \%)$ & $23 \%(12 \%-36 \%)$ & $24 \%(13 \%-36 \%)$ \\
Moderate GPS & $19 \%(10 \%-30 \%)$ & $14 \%(6 \%-24 \%)$ & $15 \%(7 \%-26 \%)$ & $16 \%(8 \%-26 \%)$ \\
Severe GPS & $4 \%(0 \%-11 \%)$ & $2 \%(0 \%-7 \%)$ & $2 \%(0 \%-8 \%)$ & $3 \%(0 \%-9 \%)$ \\
Mild insomnia & $33 \%(27 \%-39 \%)$ & $27 \%(21 \%-33 \%)$ & $28 \%(23 \%-34 \%)$ & $29 \%(24 \%-35 \%)$ \\
Moderate insomnia & $24 \%(19 \%-29 \%)$ & $18 \%(14 \%-23 \%)$ & $20 \%(15 \%-24 \%)$ & $20 \%(17 \%-25 \%)$ \\
Severe insomnia & $7 \%(4 \%-10 \%)$ & $4 \%(2 \%-7 \%)$ & $4 \%(2 \%-7 \%)$ & $5 \%(3 \%-8 \%)$ \\
Mild PTSD & $32 \%(25 \%-40 \%)$ & $26 \%(19 \%-33 \%)$ & $27 \%(20 \%-35 \%)$ & $28 \%(22 \%-35 \%)$ \\
Moderate PTSD & $23 \%(17 \%-29 \%)$ & $17 \%(12 \%-23 \%)$ & $19 \%(14 \%-24 \%)$ & $20 \%(15 \%-25 \%)$ \\
Severe PTSD & $6 \%(3 \%-11 \%)$ & $3 \%(1 \%-7 \%)$ & $4 \%(1 \%-8 \%)$ & $5 \%(2 \%-8 \%)$ \\
\hline Note CI Conficn & & &
\end{tabular}

Note: $\mathrm{CI}=$ Confidence Interval; GPS = general psychological symptoms. 
Table 5. Comparisons with prior meta-analyses of similar topic

\begin{tabular}{|c|c|c|c|c|c|c|c|c|c|c|}
\hline \multirow{2}{*}{ Author \& year } & \multirow{2}{*}{$\begin{array}{r}\text { Last search } \\
\text { date }\end{array}$} & \multirow{2}{*}{$\begin{array}{r}\text { Number of } \\
\text { articles } \\
\left(\mathrm{K}^{*}\right)\end{array}$} & \multirow{2}{*}{$\begin{array}{r}\text { Total } \\
\text { sample } \\
\text { size }\left(\mathrm{N}^{*}\right)\end{array}$} & \multirow{2}{*}{ Population } & \multicolumn{6}{|c|}{ Prevalence rate } \\
\hline & & & & & Anxiety & Depression & Distress & GPS & Insomnia & PTSD \\
\hline Pappa et al. 2020 & April 17 & 13 & 33,062 & General HCWs & $23 \%(\mathrm{~K}=12)$ & $23 \%(\mathrm{~K}=10)$ & & & $\begin{array}{r}34 \% \\
(\mathrm{~K}=5)\end{array}$ & \\
\hline Ren et al. 2020 & April 20 & 12 & 27,475 & $\begin{array}{r}\text { General population } \\
\& \mathrm{HCWs}\end{array}$ & $25 \%$ & $28 \%$ & & & & \\
\hline $\begin{array}{l}\text { Krishnamoorthy } \\
\text { et al. } 2020\end{array}$ & April 21 & 50 & 171,571 & $\begin{array}{r}\text { General population } \\
\& \mathrm{HCWs}\end{array}$ & $26 \%(\mathrm{~K}=31)$ & $26 \%(\mathrm{~K}=28)$ & $\begin{array}{r}34 \%(\mathrm{~K} \\
=7)\end{array}$ & & $\begin{array}{r}30 \% \\
(\mathrm{~K}=5)\end{array}$ & $\begin{array}{r}27 \% \\
(\mathrm{~K}=7)\end{array}$ \\
\hline \multirow{2}{*}{$\begin{array}{l}\text { Bareeqa et al. } \\
2020\end{array}$} & \multirow{2}{*}{ April 30} & \multirow{2}{*}{19} & 62,382 & $\begin{array}{r}\text { General population } \\
\& \mathrm{HCWs}\end{array}$ & $\begin{array}{r}22 \%(\mathrm{~K}=17, \\
\mathrm{N}=57311)\end{array}$ & $\begin{array}{r}27 \%(\mathrm{~K}=19, \\
\mathrm{N}=49656)\end{array}$ & $\begin{array}{l}48 \%(\mathrm{~K}=8, \\
\mathrm{N}=18439)\end{array}$ & & & \\
\hline & & & 10,267 & Frontline $\mathrm{HCWs}$ & $\begin{array}{l}24 \%(\mathrm{~K}=8, \\
\mathrm{N}=10267)\end{array}$ & $\begin{array}{r}32 \%(\mathrm{~K}=8, \mathrm{~N}= \\
10267)\end{array}$ & & & & \\
\hline \multirow{2}{*}{ Salari et al. 2020} & \multirow{2}{*}{ June 24} & \multirow{2}{*}{7} & 2,123 & $\begin{array}{r}\text { Frontline HCWs - } \\
\text { Doctor }\end{array}$ & & & & & $42 \%$ & \\
\hline & & & 3,745 & $\begin{array}{r}\text { Frontline HCWs - } \\
\text { Nurse }\end{array}$ & & & & & $35 \%$ & \\
\hline \multirow{4}{*}{$\begin{array}{l}\text { This meta- } \\
\text { analysis }\end{array}$} & \multirow{4}{*}{ Nov. 16} & 47 & 65,477 & Frontline HCWs & $28 \%$ & $29 \%$ & $39 \%$ & $28 \%$ & $33 \%$ & $32 \%$ \\
\hline & & 47 & 71,341 & General HCWs & $22 \%$ & $23 \%$ & $32 \%$ & $21 \%$ & $27 \%$ & $26 \%$ \\
\hline & & 78 & 493,426 & $\begin{array}{r}\text { General } \\
\text { population }\end{array}$ & $23 \%$ & $24 \%$ & $34 \%$ & $23 \%$ & $28 \%$ & $27 \%$ \\
\hline & & 171 & 630,244 & Total population & $24 \%$ & $25 \%$ & $35 \%$ & $24 \%$ & $29 \%$ & $28 \%$ \\
\hline
\end{tabular}

Note: We include the existing meta-analyses that either target populations in China or whose included studies are mostly based in China (>90\%). All prevalence rates in this table are reported by the cutoff of mild and above. HCWs $=$ Healthcare workers.

$* \mathrm{~K}=$ Total number of studies on one outcome, which is smaller than total number of studies in a meta-analysis.

$\mathrm{N}=$ Total sample size on one outcome, which is smaller than total sample size in a meta-analysis 
medRxiv preprint doi: https://doi.org/10.1101/2021.02.01.21250929; this version posted April 30, 2021. The copyright holder for this preprint (which was not certified by peer review) is the author/funder, who has granted medRxiv a license to display the preprint in perpetuity.

\section{It is made available under a CC-BY-ND 4.0 International license .}

Table 6. A list of recommendations for mental health research papers

\begin{tabular}{|c|c|}
\hline & Guides for future research and reporting \\
\hline $\begin{array}{l}\text { Outcome and } \\
\text { instrument }\end{array}$ & $\begin{array}{l}\text { 1) Study health outcomes that have higher prevalence rates, e.g., distress and } \\
\text { insomnia } \\
\text { 2) Use validated instruments }\end{array}$ \\
\hline $\begin{array}{l}\text { Severity of the } \\
\text { symptoms }\end{array}$ & $\begin{array}{l}\text { 3) Use and report more levels of severity of symptoms and the cutoff points } \\
\text { used } \\
\text { 4) Specify the meaning of overall prevalence, whether above mild or above } \\
\text { moderate } \\
\text { 5) Specify the cutoff values used with the reasons/references }\end{array}$ \\
\hline $\begin{array}{l}\text { Characteristics of } \\
\text { the samples }\end{array}$ & $\begin{array}{l}\text { 6) Report sampling locations more precisely - not just the country, but the } \\
\text { region or the distance from epicenter if possible } \\
\text { 7) Report the sampling dates } \\
\text { 8) Report the age/gender of the participants }\end{array}$ \\
\hline Population & 9) Separate and focus on frontline line HCWs vs. HCWs \\
\hline Study design & 10) More future research using cohort designs \\
\hline
\end{tabular}




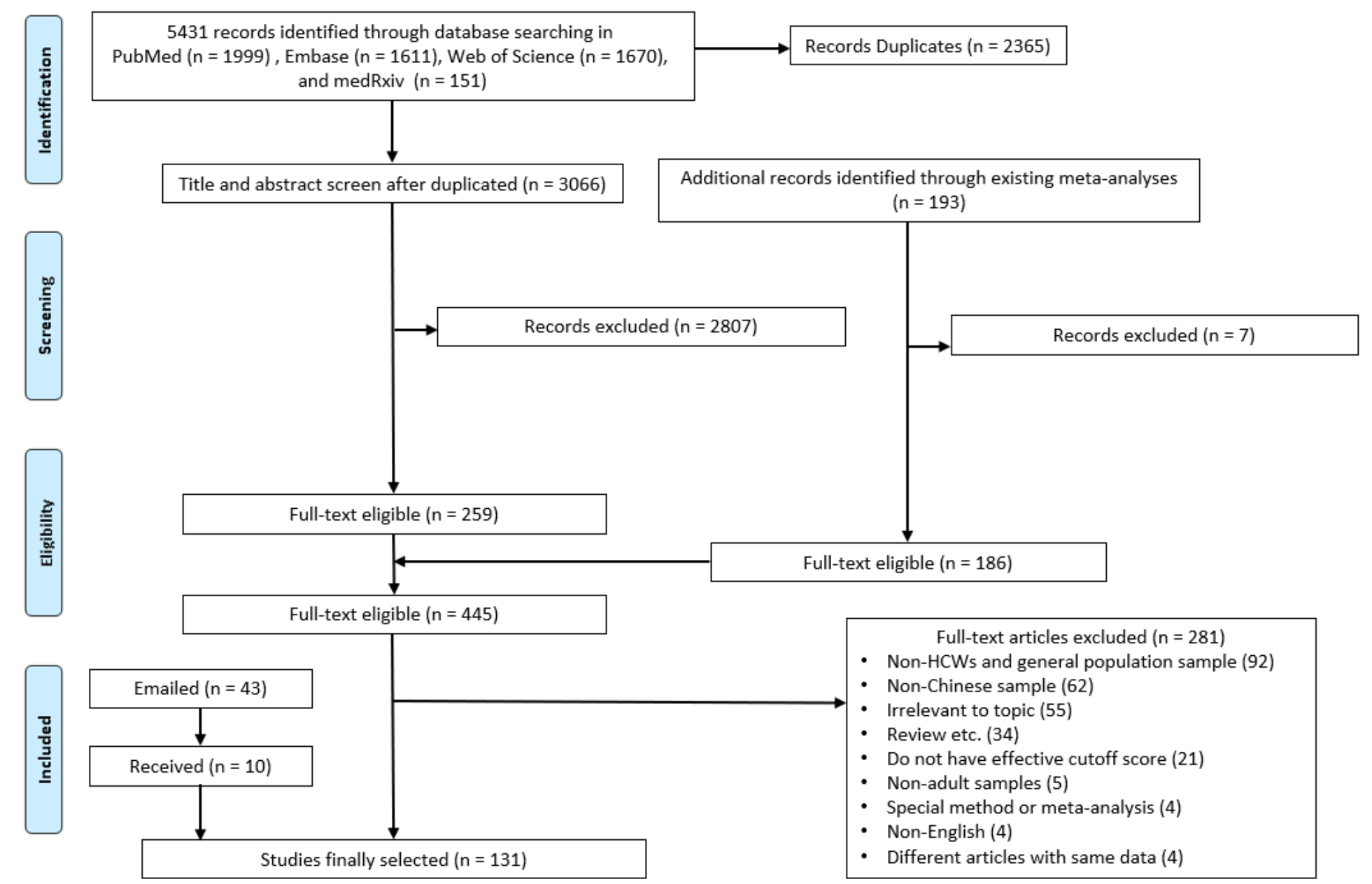

Figure 1. The PRISMA (Preferred Reporting Items for Systematic Reviews and Meta-Analysis) flow diagram 


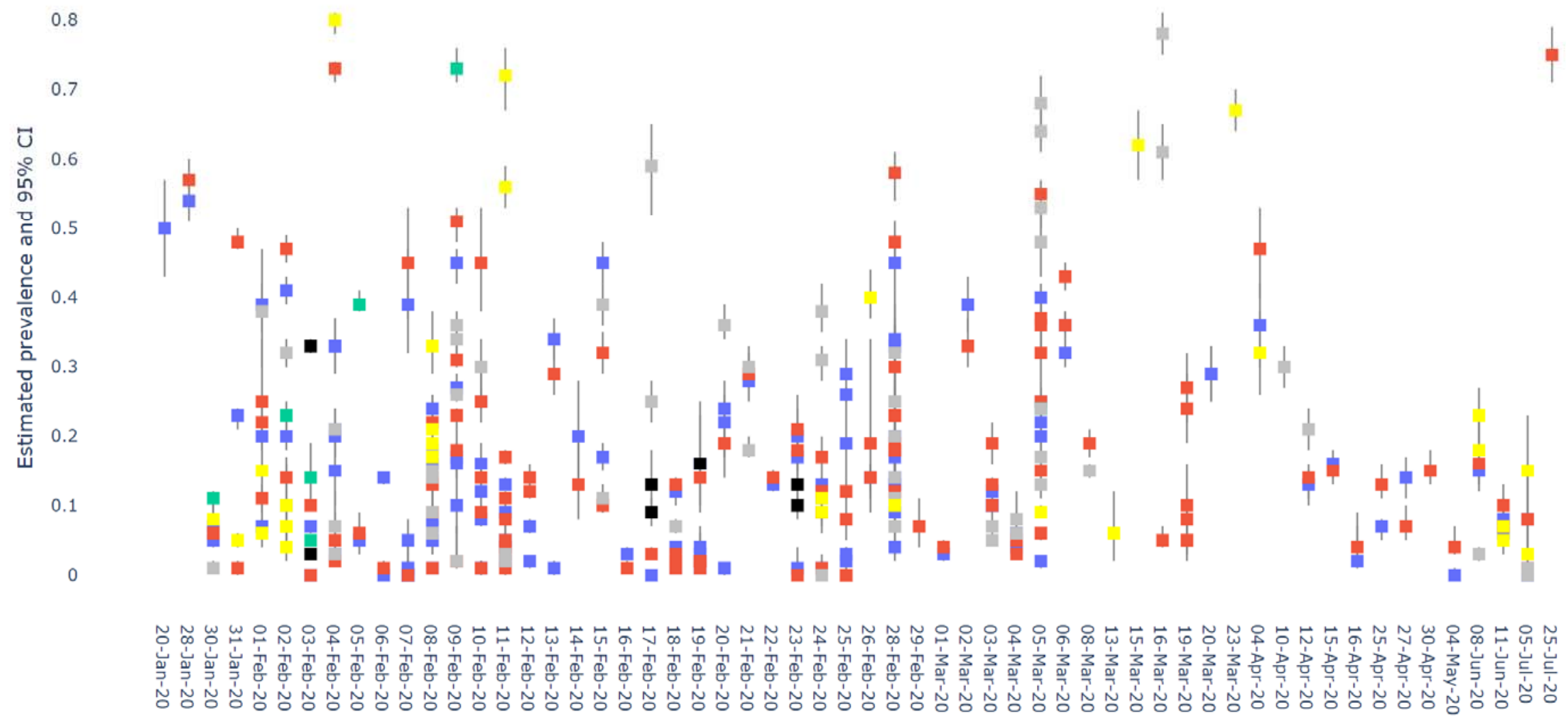

Figure 2a. A forest plot of the pooled prevalence by outcomes 
Type Above mild above moderate above severe

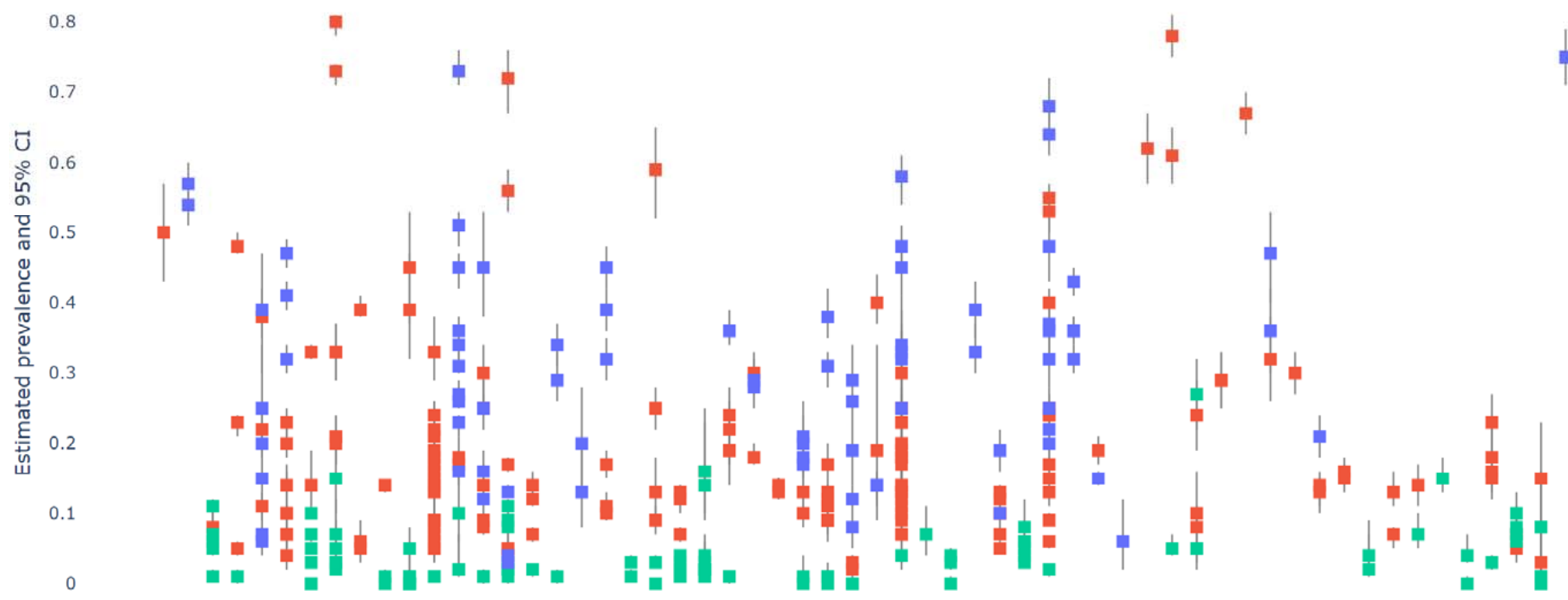

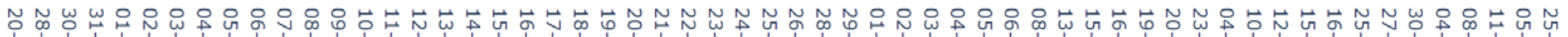

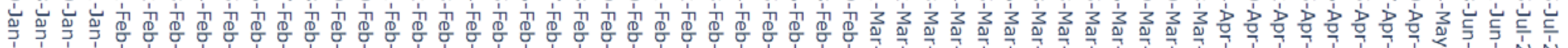

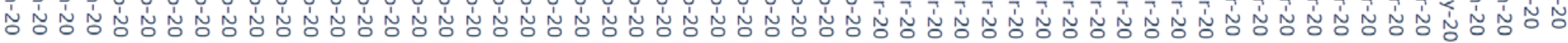

Figure 2b. A forest plot of the pooled prevalence by outcome levels 


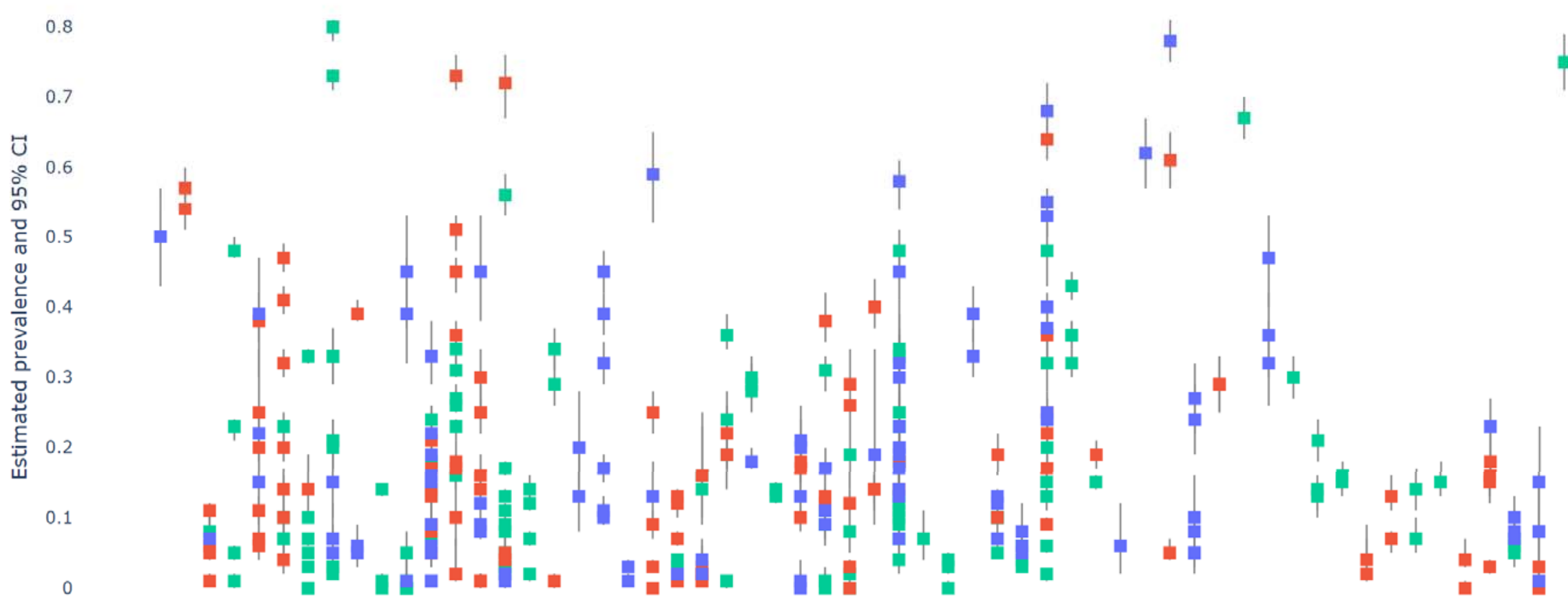

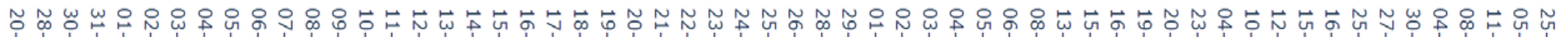

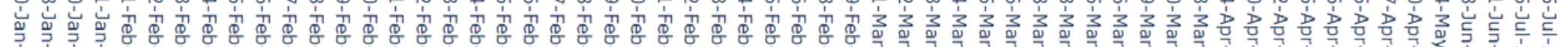

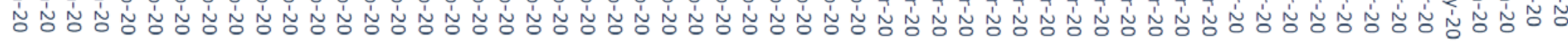

Figure 2c. A forest plot of the pooled prevalence by population 


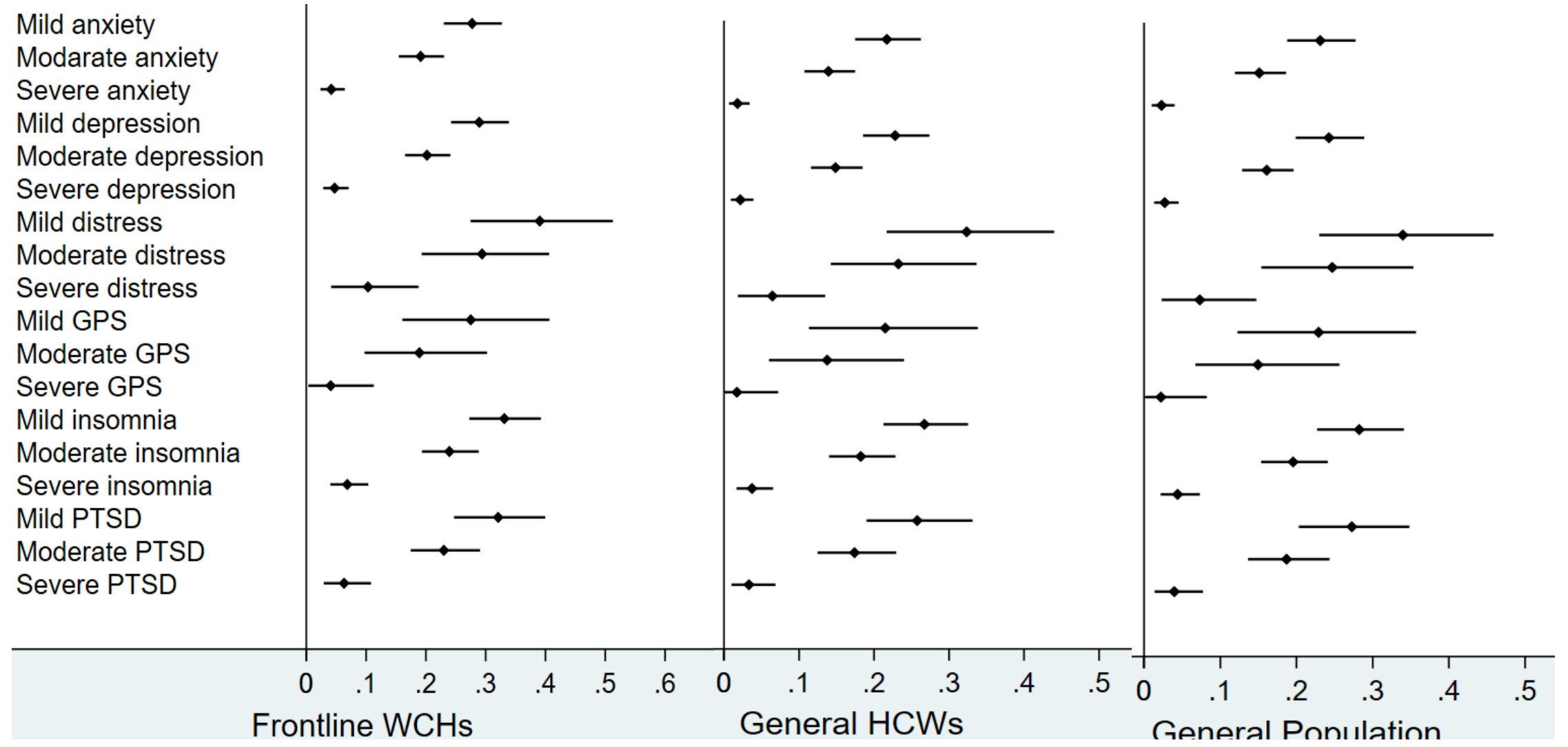

Figure 3. The predicted prevalence rates of mental health disorders by populations, outcomes, and severity by the meta-analytical regression model 
LFK index $=2.12$ (major asymmetry)

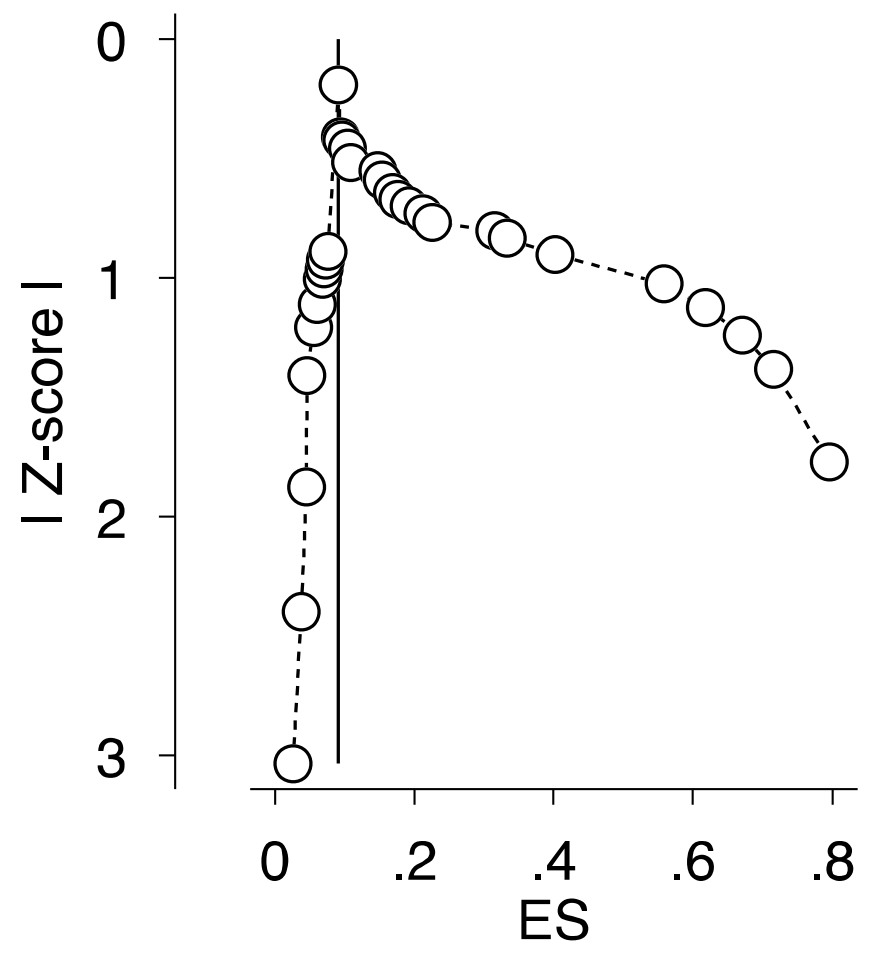

Figure 4. The DOI plot and the Luis Furuya-Kanamori (LFK) index over \pm 2 indicates 'major asymmetry' in publication bias among the studies published to date. 